Brazilian Journal

of Chemical

Engineering

\title{
CATALYST PREPARATION METHODS TO REDUCE CONTAMINANTS IN A HIGH-YIELD PURIFICATION PROCESS OF MULTIWALLED CARBON NANOTUBES
}

\author{
Laura M. Esteves ${ }^{1}$, Juliana L. Smarzaro ${ }^{1}$, Alexander Caytuero ${ }^{1}$, \\ Hugo A. Oliveira ${ }^{1 *}$ and Fabio B. Passos ${ }^{1}$
}

\begin{abstract}
${ }^{1}$ Universidade Federal Fluminense, Departamento de Engenharia Química e de Petróleo, Niterói, RJ, Brasil. E-mail: lauraesteves@id.uff.br - ORCID: 0000-0002-5458-0448; E-mail: julianasmarzaro@id.uff.br - ORCID: 0000-0002-4958-0101; E-mail: acvcaytuero@gmail.com - ORCID: 0000-00021127-4571; E-mail: hugoao@id.uff.br - ORCID: 0000-0002-1476-0495; E-mail: fabiopassos@id.uff.br - ORCID: 0000-0001-6461-8756
\end{abstract}

(Submitted: May 17, 2019 ; Revised: August 25, 2019 ; Accepted: September 2, 2019)

\begin{abstract}
CoMo/MgO catalysts with low loading of cobalt and molybdenum were prepared by incipient wetness impregnation and the sol-gel method for high yield production of carbon nanotubes (CNT). A detailed characterization of the catalysts, as-produced CNT and purified CNT, indicated a relationship between carbon nanotube properties, synthesis and purification steps. Excess of molybdenum in the catalyst caused a decrease in carbon yield and produced CNT with a lower degree of graphitization. Catalysts prepared by the sol-gel method and with higher molybdenum loading showed an improved interaction between cobalt and molybdenum, increasing the formation of $\mathrm{CoMoO}_{4}$, which was not completely removed during the purification step. The purification removed all $\mathrm{MgO}$ and part of the cobalt and molybdenum present in samples without significant damage to the CNT structure. An increase in sample purity could be achieved by increasing reaction time. Keywords: Carbon nanotube; Chemical vapor deposition; Purification.
\end{abstract}

\section{INTRODUCTION}

The production of carbon nanotubes has become interesting due to their unique properties since first reported by Ijima (1991). Then, the development and optimization of nanotube synthesis methods have been the subject of research, seeking higher carbon yields and selective processes towards materials with superior purity and quality (Xu et al., 2011). Their remarkable properties, such as high elastic modulus and tensile strength, high flexibility and elasticity, high electrical and thermal conductivity, allow the application of CNT in different fields. Studies involving the use of these materials cover areas of energy storage, biotechnology, microelectronics and catalysis (Liu et al., 2014; Wang et al., 2018).

The most commonly cited methods for carbon nanotube synthesis are laser ablation, arc-discharge and chemical vapor deposition (CVD). Among them, the CVD technique is a viable option for large-scale production, since it allows a more effective control of reaction conditions, favoring the formation of nanotubes with high quality structure and morphology. Besides, it may be carried out in milder temperatures, thereby lowering production costs (Liu et al., 2014).

Cobalt, iron and nickel catalysts, supported on silica or alumina, are frequently used in the CVD method (Tran et al., 2007). Additionally, bimetallic catalysts have demonstrated higher efficiency than monometallic catalysts in nanotube production. The addition of a promoter, such as molybdenum, vanadium or tungsten, originates a stabilizing effect, preventing the agglomeration of the catalyst active phase and improving yield and graphitization of the nanotubes (Jourdain and Bichara, 2013).

\footnotetext{
* Corresponding author: Hugo A. Oliveira - E-mail: hugoao@id.uff.br
} 
Cobalt and molybdenum supported on $\mathrm{SiO}_{2}$ and $\mathrm{Al}_{2} \mathrm{O}_{3}$ catalysts were extensively studied by several groups (Kitiyanan et al., 2000; Alvarez et al., 2001; Flahaut et al., 2003; Serquis et al., 2003; Chai et al., 2011) and catalyst parameters that influence the production and morphology of the carbon nanotubes are well known. However, the purification of CNT synthetized by catalysts supported on $\mathrm{SiO}_{2}$ and $\mathrm{Al}_{2} \mathrm{O}_{3}$ demands the use of strong acids, such as nitric acid, sulfuric acid and hydrofluoric acid. These acids may damage the carbon nanotube structure. Magnesium oxide is a good choice as catalyst support since it is easily removed through a mild hydrochloric acid treatment. The use of easily soluble catalysts in CNT production allows the application of efficient and less destructive purification processes (Yeoh et al., 2009). Moreover, it minimizes the formation of amorphous carbon and the agglomeration of metal particles during the nanotube growth process (Pudukudy et al., 2017).

$\mathrm{CoMo} / \mathrm{MgO}$ catalysts with low content of cobalt and molybdenum exhibit high yield of SWNT per gram of catalyst (Ni et al., 2006; Yardimci et al., 2015). High yield of MWNT is achieved with catalysts with high cobalt and molybdenum content, usually higher than 25 wt.\% (Ni et al., 2006; Yeoh et al., 2009, 2013; Núñez et al., 2011; Milone et al., 2014; Awadallah et al., 2014; Yardimci et al., 2015). The yield increases and the use of low-cost feedstocks, such as methane, in CNT production have decreased MWNT prices. However, for incorporation of carbon nanotubes into commonly used materials, they need to be produced on a large-scale and according to predetermined specifications and essential requirements for their industrial use.

Large-scale processes yield contaminants that can change CNT properties and usually require costly chemical treatment and thermal annealing for their removal. Thus, the purification of CNT synthesized by CVD is an important step to achieve the requirements for their applications. For example, the hydrogen uptake capacity of SWNT requires a low amount of metal particles in order to obtain high surface area (Mohanapriya and Lakshminarayanan, 2007). Also, defects within MWNT would reduce their electrical properties, which are very important in lithium ion batteries where a small amount of MWNT provides an increased electrical connectivity and mechanical integrity (De Volder et al., 2013).

Thus, this paper discusses the production and purification of high yield MWNT synthesized through methane CVD in a fluidized bed reactor over $\mathrm{CoMo} /$ $\mathrm{MgO}$ catalysts. The catalysts were prepared by the two most usual preparation methods: incipient wetness impregnation and sol-gel techniques. Two different loadings of cobalt and molybdenum were used for each catalyst preparation method: a typical loading of 5 wt.\% of Co and 20 wt.\% of Mo and another with a lower molybdenum loading, 5 wt.\% of Co and 10 wt. $\%$ of Mo. A lower molybdenum loading was used with the aim of reducing the concentration of contaminants in the final product. Then, a detailed characterization of the catalysts, as-produced MWNT and, especially, of the purified MWNT are related to the carbon nanotube synthesis and purification process.

\section{EXPERIMENTAL}

$\mathrm{CoMo} / \mathrm{MgO}$ catalysts were prepared by incipient wetness impregnation and the sol-gel method. The amount of precursors used in both methods was suitable to obtain catalysts with weight ratios of 5:10:85 and 5:20:75 of Co:Mo:MgO. In the case of the impregnation method, $\mathrm{MgO}$ (97\%, Merck) was impregnated with an aqueous solution prepared with stoichiometric amounts of $\mathrm{Co}\left(\mathrm{NO}_{3}\right)_{2} \cdot 6 \mathrm{H}_{2} \mathrm{O} \quad(98 \%$, Sigma-Aldrich) and $\left(\mathrm{NH}_{4}\right)_{6} \mathrm{Mo}_{7} \mathrm{O}_{24} \cdot 4 \mathrm{H}_{2} \mathrm{O} \quad(99 \%$, Vetec). The impregnated samples were dried at $120^{\circ} \mathrm{C}$ and calcined at $550{ }^{\circ} \mathrm{C}$ for $2 \mathrm{~h}$. For the sol-gel method, aqueous solutions were prepared with stoichiometric amounts of $\mathrm{Co}\left(\mathrm{NO}_{3}\right)_{2} \cdot 6 \mathrm{H}_{2} \mathrm{O}$ (98\%, Sigma-Aldrich), $\left(\mathrm{NH}_{4}\right)_{6} \mathrm{Mo}_{7} \mathrm{O}_{24} \cdot 4 \mathrm{H}_{2} \mathrm{O}(99 \%$, Vetec $)$ and $\mathrm{Mg}\left(\mathrm{NO}_{3}\right)_{2} \cdot 6 \mathrm{H}_{2} \mathrm{O}$ (98\%, Sigma-Aldrich) along with $10 \mathrm{~g}$ of citric acid. Then, the mixtures were stirred at $90{ }^{\circ} \mathrm{C}$ for $1 \mathrm{~h}$. The resulting viscous mixtures were dried at $120{ }^{\circ} \mathrm{C}$ and calcined at $550{ }^{\circ} \mathrm{C}$. The catalysts were denoted as $5 \mathrm{Co} 10 \mathrm{Mo}_{\mathrm{Imp}}, \quad 5 \mathrm{Co} 20 \mathrm{Mo}_{\mathrm{Imp}}, \quad 5 \mathrm{Co} 10 \mathrm{Mo}_{\mathrm{SG}}$ and $5 \mathrm{Co} 20 \mathrm{Mo}_{\mathrm{SG}}$.

The CNT production was performed in a vertical fluidized bed reactor, using $1 \mathrm{~g}$ of catalyst, by the methane CVD method. The process was performed by continuous heating from room temperature to $800{ }^{\circ} \mathrm{C}$ at a rate of $10^{\circ} \mathrm{C} / \mathrm{min}$. Initially, the catalyst was heated under a $\mathrm{H}_{2}$ flow $(150 \mathrm{~mL} / \mathrm{min})$ until $500^{\circ} \mathrm{C}$. Then, the flow was switched to $\mathrm{N}_{2}(150 \mathrm{~mL} / \mathrm{min})$ until the synthesis temperature of $800{ }^{\circ} \mathrm{C}$ was reached. At the synthesis temperature, the $\mathrm{N}_{2}$ flow was replaced by $\mathrm{CH}_{4}$ gas (150 $\mathrm{mL} / \mathrm{min}$ ) for $30 \mathrm{~min}$. At the end of the reaction, $\mathrm{CH}_{4}$ gas was turned off and the reactor was cooled to room temperature under a $\mathrm{N}_{2}$ flow. The as-produced CNT were denoted as CNT.5 Co10Mo ${ }_{\text {Imp }}$, CNT.5Co10 $\mathrm{Mo}_{\mathrm{SG}}$, CNT.5Co20 $\mathrm{Mo}_{\text {Imp }}$ and CNT.5Co20 $\mathrm{Mo}_{\mathrm{SG}}$.

For purification of the as-produced CNT, $0.4 \mathrm{~g}$ of as-produced CNT were macerated and then mixed with $100 \mathrm{~mL}$ of a $0.3 \mathrm{M} \mathrm{HCl}$ solution. Each solution was agitated for $2 \mathrm{~h}$, sonicated for $30 \mathrm{~min}$ and agitated again for $2 \mathrm{~h}$. The solution was aged for $8 \mathrm{~h}$ and then it was filtrated and rinsed with deionized water until $\mathrm{pH}$ 7. Finally, the product was dried at $120^{\circ} \mathrm{C}$ for $12 \mathrm{~h}$. The purified samples were designed as CNTp.5Co10 $\mathrm{Mo}_{\text {Imp }}$, CNTp. $5 \mathrm{Co} 10 \mathrm{Mo}_{\mathrm{SG}}, \quad \mathrm{CNTp} .5 \mathrm{Co} 20 \mathrm{Mo}_{\mathrm{Imp}}$ and CNTp.5Co20Mo ${ }_{\mathrm{SG}}$.

X-ray diffraction (XRD) analysis was performed with a Rigaku Miniflex II X-ray diffractometer using monochromatic $\mathrm{Cu}-\mathrm{K} \alpha$ radiation $(\lambda=1.540 \AA)$. The 
XRD patterns of the catalysts, as-produced and purified CNT were recorded in a $2 \theta$ range of $10^{\circ}-100^{\circ}$, with a step of $0.02^{\circ}$ and measuring time of $1 \mathrm{~s}$ per point.

Surface area, average pore diameter and pore volume of the calcined catalysts were determined by $\mathrm{N}_{2}$ adsorption in a Micromeritics ASAP 2020 analyzer, with sample weights around 0.2-1.0 g. The samples were dried at $150{ }^{\circ} \mathrm{C}$ and degassed at $150{ }^{\circ} \mathrm{C}$ for $2 \mathrm{~h}$ under vacuum before analysis. The surface area was obtained by the BET (Brunauer, Emmett and Teller) method and the average pore diameter and pore volume were obtained by the BJH (Barrett, Joyner and Halenda) method.

Energy dispersive X-ray spectrometry (EDX) analysis of the calcined catalyst and purified samples were performed with a Shimadzu EDX-720 spectrometer in vacuum $(<30 \mathrm{~Pa})$ to determine the chemical compositions of the materials.

Temperature programmed reduction (TPR) experiments were carried out in an U-shaped quartz reactor using 200-300 $\mathrm{mg}$ of calcined catalyst. The samples were dried at $300^{\circ} \mathrm{C}$ under a He flow of $30 \mathrm{~mL} /$ min during $50 \mathrm{~min}$. After cooling, the reduction was performed with a mixture of $5 \% \mathrm{H}_{2} / \mathrm{Ar}$ at $30 \mathrm{~mL} / \mathrm{min}$ from room temperature to $1000{ }^{\circ} \mathrm{C}$ with a heating rate of $10^{\circ} \mathrm{C} / \mathrm{min}$ and the temperature was held constant at $1000{ }^{\circ} \mathrm{C}$ for $1 \mathrm{~h}$. The $\mathrm{H}_{2}$ consumption was monitored with a Pfeiffer Prisma mass spectrometer connected to the equipment.

X-ray photoelectron spectroscopy (XPS) analysis for the catalysts was performed with a Thermo Scientific ESCALAB 250Xi spectrometer using a monochromatic Al-Ka X-ray source $(1486,7 \mathrm{eV})$. High-resolution spectra were collected with a pass energy of $25.0 \mathrm{eV}$, energy step of $0.05 \mathrm{eV}$ and dwell time of $50 \mathrm{~ms}$. Charging effects were minimized with a low energy electron flood gun. During analysis, the pressure was kept around $10^{-8} \mathrm{mbar}$ inside the analysis chamber. The peak positions in the spectra were corrected using as reference the $\mathrm{C} 1 \mathrm{~s}$ peak $(284.5 \mathrm{eV})$.

Thermogravimetric analysis (TGA) was performed with a Shimadzu DTG-60H differential thermal gravimetric analyzer to quantify the weight loss of the as-produced and purified CNT. The analysis was carried out in an atmosphere of $5 \% \mathrm{O}_{2} / \mathrm{He}$ with a flow rate of $30 \mathrm{~mL} / \mathrm{min}$ from room temperature to $1000{ }^{\circ} \mathrm{C}$ with a heating rate of $5^{\circ} \mathrm{C} / \mathrm{min}$. The carbon yield was calculated using Eq. (1):

$\mathrm{C}_{\text {Yield }}(\%)=\frac{\mathrm{m}_{\text {carbon }}}{\mathrm{m}_{\text {catalyst }}} \times 100$

where $\mathrm{m}_{\text {carbon }}$ is the carbon weight loss during TGA analysis and $m_{\text {catalyst }}$ is the weight of the catalyst after sample oxidation obtained at the end of the TGA.

The sample purity was estimated by Eq. (2):
$\operatorname{Purity}(\%)=\frac{\mathrm{m}_{\text {carbon }}}{\left(\mathrm{m}_{\text {carbon }}+\mathrm{m}_{\text {impurities }}\right)} \times 100$

where $m_{\text {inpuruties }}$ is the weight of cobalt, molybdenum and magnesium at the end of the TGA.

Temperature programmed oxidation (TPO) experiments were carried out in an U-shaped quartz reactor using $20 \mathrm{mg}$ of the as-produced and purified CNT. The samples were dried at $200{ }^{\circ} \mathrm{C}$ for $30 \mathrm{~min}$ under $\mathrm{He}$ with a flow rate of $30 \mathrm{~mL} / \mathrm{min}$. After cooling, the oxidation was performed with a mixture of $5 \%$ $\mathrm{O}_{2} / \mathrm{He}$ with a flow rate of $30 \mathrm{~mL} / \mathrm{min}$ from room temperature to $1000^{\circ} \mathrm{C}$ at a rate of $5^{\circ} \mathrm{C} / \mathrm{min}$. The $\mathrm{CO}_{2}$ production was monitored with a Pfeiffer Prisma mass spectrometer connected to the equipment.

Raman spectra of the catalysts, as-produced and purified CNT were obtained in a Witec alpha 300 Confocal Raman Microscope, using a 50x objective lens and a $532 \mathrm{~nm}$ excitation laser wavelength. The diameter of the single walled carbon nanotubes was estimated by equation 3 (Rols et al. 2000):

$v_{\mathrm{RBM}}=\frac{238}{\mathrm{~d}^{0.93}}$

where $v_{\text {RBM }}\left(\mathrm{cm}^{-1}\right)$ is the wavelength and $d$ is the nanotube diameter $(\mathrm{nm})$.

The as-produced and purified CNT were also characterized by scanning electron microscopy (SEM) in a JEOL JSM-7100F microscope and by transmission electron microscopy (TEM) with a JEOL JEM-1011 microscope. The samples were prepared by sonication of the as-produced CNT in isopropyl alcohol. A few drops of the resulting suspension were deposited on a copper support grid and dried at room temperature.

\section{RESULTS AND DISCUSSION}

\section{Characterization of the catalysts}

The chemical compositions of catalysts and purified CNT were analyzed by EDX. The catalyst composition is consistent with the nominal values used in the catalyst preparation (Table 1). The EDX spectrometer used in the experiments is equipped with a beryllium window, so the detectors cannot detect X-rays from elements lighter than sodium, including carbon and oxygen X-rays. Thus, $\mathrm{MgO}$ weight percentage was estimated by stoichiometry.

The values of surface area $\left(\mathrm{S}_{\mathrm{BET}}\right)$, pore volume $\left(\mathrm{V}_{\mathrm{p}}\right)$ and the average pore diameter of catalysts $\left(\mathrm{D}_{\mathrm{p}}\right)$ prepared by the impregnation method were slightly higher than the values found for the support. This behavior is due to the destruction of the $\mathrm{MgO}$ original texture with face centered cubic structure in function of its hydration during the impregnation step, which 
Table 1. Sample chemical composition obtained by EDX. Surface area $\left(\mathrm{S}_{\mathrm{BET}}\right)$, pore volume $(\mathrm{Vp})$ and average pore diameter analyzed by $\mathrm{N}_{2}$ physisorption. Ratio between the most intense peak at $26.3^{\circ}$ (related to $\mathrm{MgMoO}_{4}$ or $\mathrm{CoMoO}_{4}$ ) and the most intense peak of $\mathrm{MgO}$ at $42.9^{\circ}$.

\begin{tabular}{|c|c|c|c|c|c|c|c|}
\hline \multirow{2}{*}{ Samples } & \multicolumn{3}{|c|}{ Composition / wt.\% } & \multirow{2}{*}{$\begin{array}{c}\mathrm{S}_{\mathrm{BET}} / \\
\left(\mathrm{m}^{2} \mathbf{g}^{-1}\right)\end{array}$} & \multirow{2}{*}{$\begin{array}{c}\mathbf{V}_{\mathbf{p}} / \\
\left(\mathbf{c m}^{3 /} / \mathbf{g}^{-1}\right)\end{array}$} & \multirow{2}{*}{$\mathbf{D}_{\mathbf{p}} / \mathbf{n m}$} & \multirow[b]{2}{*}{${ }^{*} \mathrm{XRD}_{26.3^{\circ} / 42.9^{\circ}}$} \\
\hline & Co & Mo & MgO & & & & \\
\hline $\mathrm{MgO}$ & - & - & - & 27 & 0.12 & 17 & - \\
\hline 5Co10MOImp & 5.5 & 11.8 & 82.7 & 52 & 0.35 & 25 & 0.04 \\
\hline 5Co10MosG & 5.2 & 9.0 & 85.8 & 36 & 0.27 & 30 & 0.13 \\
\hline 5Co20MoImp & 4.7 & 20.4 & 74.9 & 71 & 0.36 & 19 & 0.11 \\
\hline 5Co20MosG & 4.6 & 16.9 & 78.5 & 37 & 0.3 & 34 & 0.36 \\
\hline
\end{tabular}

* Ratio between the most intense peak of $\mathrm{MgMoO}_{4}$ or $\mathrm{CoMoO}_{4}$ at $26.3^{\circ}$ and the most intense peak of $\mathrm{MgO}$ at $42.9^{\circ}$.

leads to the production of $\mathrm{Mg}(\mathrm{OH})_{2}$ with hexagonal close-packed structure (Chang et al., 1992). $\mathrm{H}_{2} \mathrm{O}$ evolution during calcination, along with the structure changes, caused a surface area enhancement (Zdražil, 2003). The low surface area observed for the catalysts prepared by the sol-gel method may be related to the phenomenon of pore collapse. As already reported by Hench and West (1990), solvent evaporation during the drying process of the catalyst can cause the collapse of its structure, in particular, the collapse of pores smaller than $20 \mathrm{~nm}$, reducing its surface area due to the formation of a xerogel.

XRD analyses were performed to identify and analyze the crystallite phases in the $\mathrm{CoMo} / \mathrm{MgO}$ catalysts, as shown in Figure 1. The most intense peaks of the catalysts were identified as diffraction lines of $\mathrm{MgO}$ (Wang et al. 2012) in $2 \theta=36.9^{\circ} ; 42.8^{\circ}$; $62.3^{\circ}$; which match with the standard data (JCPDS no. 45-0946).

Intense peaks were also observed at $2 \theta=19.1^{\circ}$, $23.0^{\circ}$ and $26.3^{\circ}$, which can be assigned to the most intense peaks of $\mathrm{MgMoO}_{4}$ or $\mathrm{CoMoO}_{4}$ patterns (JCPDS no. 72-2153 and 21-868 respectively). These species have approximately the same diffraction pattern. The formation of these species has been observed in the

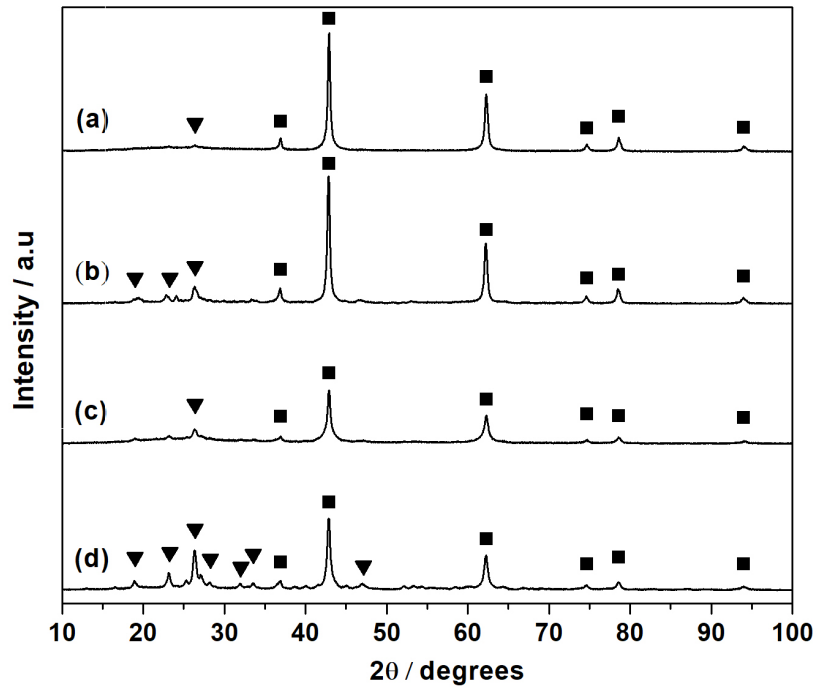

Figure 1. XRD patterns of the $\mathrm{CoMo} / \mathrm{MgO}$ catalysts:

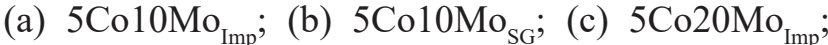
(d) $5 \mathrm{Co}^{2} 2 \mathrm{Mo}_{\mathrm{SG}^{\circ}}$ ( $\left.\mathbf{m}\right) \mathrm{MgO},(\boldsymbol{\nabla}) \mathrm{MgMoO}_{4}$ or $\mathrm{CoMoO}_{4}$. case of $\mathrm{CoMo} / \mathrm{MgO}$ catalysts calcined at temperatures above $400{ }^{\circ} \mathrm{C}$ (Radwan et al., 2003). In XRD patterns of the catalysts prepared with the sol-gel method, the intensity of $\mathrm{MgMoO}_{4}$ or $\mathrm{CoMoO}_{4}$ peaks in relation to $\mathrm{MgO}$ diffraction peaks were higher when compared with catalysts prepared by impregnation. Also, an increase in molybdenum loading increased the intensity of those peaks. The value of the ratio between the most intense peak of $\mathrm{MgMoO}_{4}$ or $\mathrm{CoMoO}_{4}$ at 26.3 ${ }^{\circ}$ and the most intense peak of $\mathrm{MgO}$ at $42.9^{\circ}$ can be observed in Table 1.

Some minor diffraction peaks of $\mathrm{MoO}_{2}$ were observed at $36.7^{\circ}, 53.4^{\circ}, 56.9^{\circ}, 60.3^{\circ}, 69.1^{\circ}, 71.9^{\circ}$, $73.2^{\circ}$ and $80.9^{\circ}$ (JCPDS no. 78-1072), for sol-gel prepared catalysts. No diffraction peaks of $\mathrm{MoO}_{3}$ were identified (JCPDS no. 76-1003) in any of the catalysts.

The characteristic patterns of cobalt species, such as $\mathrm{Co}_{3} \mathrm{O}_{4}$ which has the most intense peaks in $2 \theta=$ $31.3^{\circ} ; 36.8^{\circ}$ and $65.2^{\circ}$ (JCPDS no. 43-1003), were not observed. The interaction between magnesium and cobalt oxides may lead to formation of a $\mathrm{CoO}-$ $\mathrm{MgO}$ solid solution. In this case, $\mathrm{Co}^{+2}$ ions enter into the $\mathrm{MgO}$ lattice, as discussed by Ulla et al. (2001), and it causes similarities between the patterns of the solid solution and $\mathrm{MgO}$. It is important to highlight that complete dissolution of $\mathrm{Co}^{2+}$ into the $\mathrm{MgO}$ lattice only occurs at temperatures above $800{ }^{\circ} \mathrm{C}$ (Radwan et al. 2003). Also, the three most intense peaks of $\mathrm{CoO}$ (JCPDS no. 65-0902) at $2 \theta=36.5^{\circ} ; 42.4^{\circ}$ and $61.5^{\circ}$ are very close to the three most intense peaks of $\mathrm{MgO}$. As a result, diffraction patterns of $\mathrm{MgO}$ and $\mathrm{CoO}$ may overlap (Wang et al., 2012).

$\mathrm{H}_{2}$ TPR profiles of the support and calcined catalysts are presented in Figure 2. The reduction profile of the pure $\mathrm{MgO}$ did not exhibit hydrogen consumption as reported before by Parmaliana et al. (1990). All catalysts exhibited three reduction peaks: the first small peak, at $380{ }^{\circ} \mathrm{C}$, may be assigned to the reduction of cobalt particles with weak metalsupport interaction, possibly in the form of $\mathrm{Co}_{3} \mathrm{O}_{4}$. It has been reported that reduction of $\mathrm{Co}_{3} \mathrm{O}_{4}$ happens in a stepwise process around $250-380{ }^{\circ} \mathrm{C}$ for bulk $\mathrm{Co}_{3} \mathrm{O}_{4}$ and around $470-520{ }^{\circ} \mathrm{C}$ for $\mathrm{Co} / \mathrm{MgO}$ (Kaluža et al., 2007). As the hydrogen consumption was very small in the temperature range of typical $\mathrm{Co}_{3} \mathrm{O}_{4}$ reduction, 


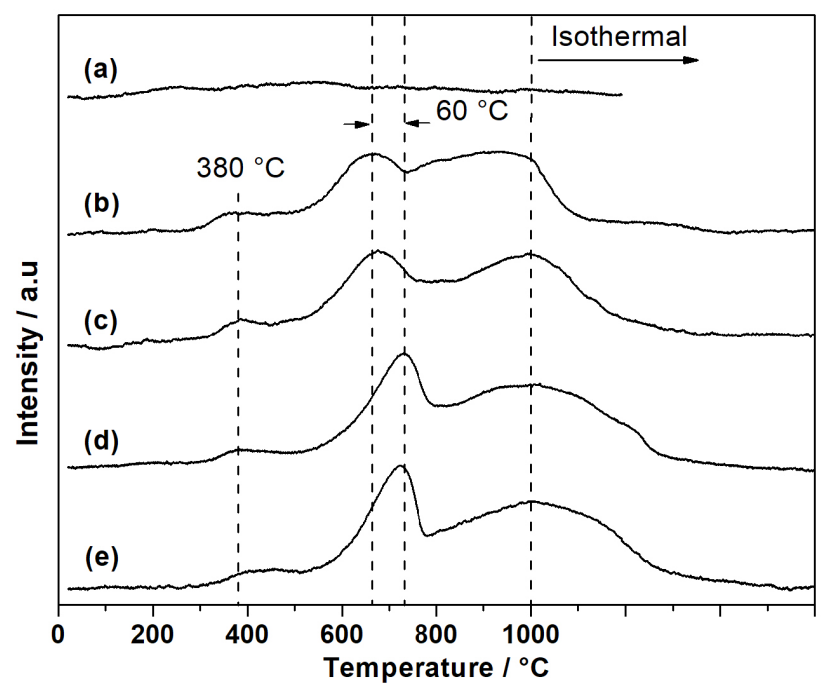

Figure 2. TPR profiles of the support and catalysts:

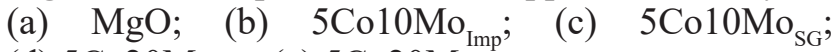
(d) $5 \mathrm{Co} 20 \mathrm{Mo}_{\mathrm{Imp}}$; (e) $5 \mathrm{Co} 20 \mathrm{Mo}_{\mathrm{SG}}$ '

the major reduction of the cobalt species has shifted to higher temperatures.

The second peak around $660-720{ }^{\circ} \mathrm{C}$ may be attributed to reduction of $\mathrm{CoMoO}_{4}$ and stepwise reduction of molybdenum species, such as $\mathrm{MoO}_{3}$ (Wang et al., 2012). There is a $60^{\circ} \mathrm{C}$ shift towards higher temperatures of the second peak for catalysts with $20 \mathrm{wt} . \%$ of Mo as compared to the catalysts with 10 wt. $\%$ of Mo.

The third peak, obtained above $800^{\circ} \mathrm{C}$, and during the isothermal period, may be attributed to the reduction of three different compounds: $\mathrm{CoO}-\mathrm{MgO}$ solid solution (Wang and Ruckenstein 2002), reduction of $\mathrm{MgMoO}_{4}$ (Awadallah et al., 2014) and reduction of $\mathrm{MoO}_{2}$ species that correspond to a stepwise reduction of $\mathrm{Mo}^{2+}$ to $\mathrm{Mo}^{0}$ (Medema et al., 1978).

XRD and TPR results showed that the calcined catalysts have many cobalt, molybdenum and magnesium oxide species and some of them are reduced at the same temperature range, which made it difficult to identify and quantify these oxides. The TPR analysis could not help in identification of the diffraction lines at $2 \theta=19.1^{\circ}, 23.0^{\circ}$ and $26.3^{\circ}$, which can be assigned to $\mathrm{MgMoO}_{4}$ or $\mathrm{CoMoO}_{4}$ patterns. Both compounds may be present in catalysts as pointed by TPR profile.

As the catalysts have several cobalt, molybdenum and magnesium species, the degree of reduction was calculated by the integration all along the TPR curve and considering $\mathrm{Co}_{3} \mathrm{O}_{4}$ and $\mathrm{MoO}_{3}$ as precursors of $\mathrm{Co}^{0}$ and $\mathrm{Mo}^{0}$ respectively. All the studied catalysts presented similar degrees of reduction, approximately $70 \%$. Kaluža et al. (2007) studied the effect of the support in the reduction of $\mathrm{Co} / \mathrm{Mo}$ catalysts and they found that the $12.4 \% \mathrm{Co} 20.6 \% \mathrm{Mo} / \mathrm{MgO}$ catalyst has a degree of reduction close to value found in our experiment, about $75 \%$.
XPS was performed to evaluate the surface chemical composition of the catalysts. Co $2 p$ photoelectron spectra of the calcined catalysts are shown in Figure $\mathrm{S} 1$. Co $2 \mathrm{p}_{3 / 2}$ peak centers were identified with binding energies between 780.4-781.0 eV and there was a spin-orbit-splitting varying between 15.6-15.8 eV. Besides, it was possible to observe characteristic shakeup satellites in the recorded spectra. These features are characteristic of $\mathrm{CoO}$ and $\mathrm{CoMoO}_{4}$ compounds (Mcintyre et al., 1990) The surface and the bulk phase have, approximately, the same cobalt compounds.

The Mo $3 \mathrm{~d}$ photoelectron spectra of the calcined catalysts are also shown in Figure $\mathrm{S} 1$. The $3 \mathrm{~d}_{5 / 2}$ line of Mo is centered in binding energies between 231.9-232.7 eV. These values are within the range of the binding energies of $\mathrm{Mo}^{+6}$ species, such as $\mathrm{MoO}_{3}$ and $\mathrm{CoMoO}_{4}$ (Mcintyre et al., 1990).

Figure 3 shows the Raman spectra of the support and calcined catalysts. The Raman spectrum of the $\mathrm{MgO}$ support did not exhibit any Raman active band, as also reported in the literature (Ulla et al., 2001). All Raman spectra of the catalysts showed the presence of characteristic vibrational modes of $\mathrm{Co}_{3} \mathrm{O}_{4}$. The spectrum of the catalysts prepared by the impregnation method, Figure 3 (b) and (d), presented $\mathrm{Co}_{3} \mathrm{O}_{4}$ bands with higher intensity than the catalysts prepared by the sol-gel method. The bands placed at 195, 483, 527 and $686 \mathrm{~cm}^{-1}$ are assigned to the vibrational modes from $\mathrm{Co}_{3} \mathrm{O}_{4}$ (Gwag and Sohn, 2012).

There were not any bands at 455 and $675 \mathrm{~cm}^{-1}$, which would be assigned to the vibrational modes of $\mathrm{CoO}$ (Tang et al., 2008). However, the presence of this species may not be ruled out, since it might be oxidized

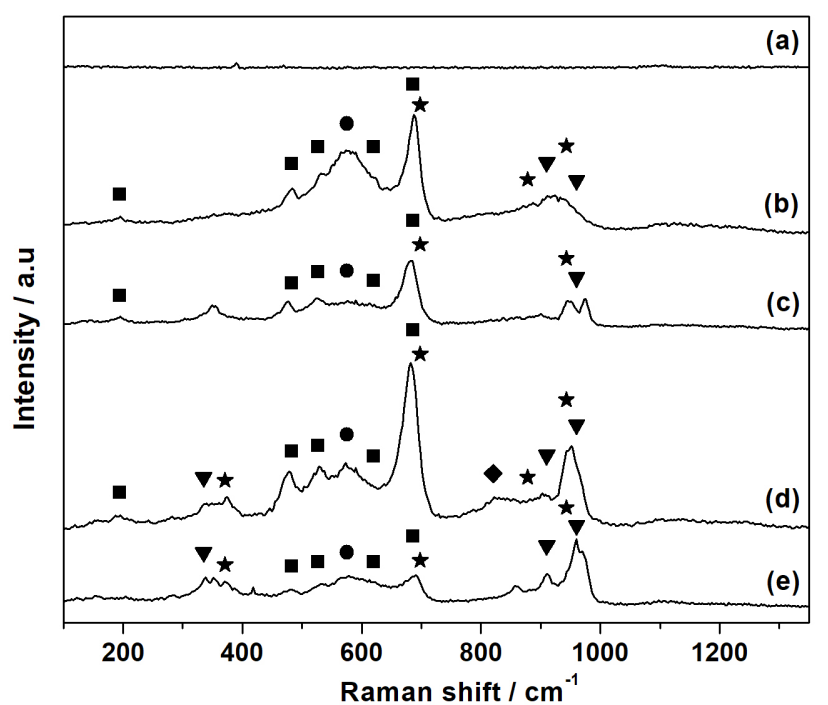

Figure 3. Raman spectra of the support and calcined catalysts: (a) $\mathrm{MgO}$; (b) $5 \mathrm{Co} 10 \mathrm{Mo}_{\mathrm{Imp}}$; (c) $5 \mathrm{Co} 10 \mathrm{Mo}_{\mathrm{SG}}$; (d) $5 \mathrm{Co} 20 \mathrm{Mo}_{\mathrm{Imp}} ;$ (e) $5 \mathrm{Co} 20 \mathrm{Mo}_{\mathrm{SG}} \cdot$ (a) $\mathrm{Co}_{3} \mathrm{O}_{4}$, ( $) \mathrm{MgMoO}_{4},(\bullet) \mathrm{CoO}-\mathrm{MgO}$ solid solution, (४) $\mathrm{MoO}_{3},(*) \mathrm{CoMoO}_{4}$. 
to $\mathrm{Co}_{3} \mathrm{O}_{4}$ due to the laser intensity used during the Raman analysis. A broad band placed at $575 \mathrm{~cm}^{-1}$ was attributed to $\mathrm{CoO}-\mathrm{MgO}$ solid solution, where $\mathrm{Co}^{2+}$ ions replace $\mathrm{Mg}^{2+}$ atoms in the $\mathrm{MgO}$ lattice. Ulla et al. (2001) reported the characterization of $\mathrm{Co} / \mathrm{MgO}$ catalysts and the $\mathrm{CoO}-\mathrm{MgO}$ solid solution. They observed a broad band at $580 \mathrm{~cm}^{-1}$, which was attributed to the partial formation of the solid solution in the $\mathrm{Co} / \mathrm{MgO}$ catalyst. They also found the possibility of the simultaneous observation of this band and the band of $\mathrm{Co}_{3} \mathrm{O}_{4}$.

Bands attributed to $\mathrm{MgMoO}_{4}$ were observed at 335, 910 and $960 \mathrm{~cm}^{-1}$ (Chang et al., 1992). Increases in the intensity of these bands were also observed for the catalysts with higher molybdenum loading. The catalyst $5 \mathrm{Co} 20 \mathrm{Mo}_{\text {Imp }}$ showed the presence of $\mathrm{MoO}_{3}$ through the attribution of the band located at $820 \mathrm{~cm}^{-1}$ (Chang et al., 1992). The formation of $\mathrm{CoMoO}_{4}$ was also observed through the identification of the bands at $371,698,878$ and $943 \mathrm{~cm}^{-1}$ and it was more intense in the case of the $5 \mathrm{Co} 20 \mathrm{Mo}_{\mathrm{SG}}$ catalyst (Moura et al., 2012).

The catalyst characterization techniques confirmed the presence of different cobalt and molybdenum compounds such as $\mathrm{CoMoO}_{4}, \mathrm{MgMoO}_{4}, \mathrm{Co}_{3} \mathrm{O}_{4}$, $\mathrm{CoO}-\mathrm{MgO}$ and $\mathrm{MoO}_{3}$. The catalyst method preparation and the molybdenum loading only affected the relative amount of each compound in the catalysts. The catalysts with $20 \mathrm{wt} \%$ of molybdenum have a higher fraction of cobalt interacting with molybdenum, such as in $\mathrm{CoMoO}_{4}$ species, especially in the $5 \mathrm{Co} 20 \mathrm{Mo}_{\mathrm{SG}}$ catalyst. However, their quantification could not be estimated due to signal overlaps of these compounds in many analyses.

The catalyst properties are very important in carbon nanotube synthesis. Under the reaction conditions, only small metallic cobalt particles are able to produce carbon nanotubes. So, cobalt oxides, precursors of metallic cobalt, should be well dispersed. XRD analyses could not detect $\mathrm{CoO}$ or $\mathrm{Co}_{3} \mathrm{O}_{4}$ crystallites. This indicates that these oxide species are well dispersed on the catalyst support. TPR, Raman spectroscopy and XPS analysis showed that a fraction of the cobalt is interacting with molybdenum. Cobalt-molybdenum interaction is an important catalyst property because molybdenum is responsible for stabilization of cobalt particle size under the reaction conditions, avoiding cobalt agglomeration. Moreover, molybdenum can also decompose methane, modifying the carbon feed for CNT growth.

For CNT production, catalysts were previously reduced in a hydrogen flow for catalyst activation. The reduction temperature of the catalysts for CNT production was chosen from TPR profiles, i.e., 500 ${ }^{\circ} \mathrm{C}$. At this temperature, $\mathrm{Co}_{3} \mathrm{O}_{4}$ and $\mathrm{CoMoO}_{4}$ species initiate their reduction. Higher temperatures during catalyst reduction may lead to sintering of the cobalt particles, which inhibit the nanotube growth, but lower temperatures may not allow enough activation of catalysts.

\section{Characterization of the as-produced and purified CNT}

Carbon nanotubes were characterized after the reaction step in the presence of catalysts, named "as-produced CNT", and after catalyst removal by purification with mild hydrochloric acid treatment, named "purified CNT".

The SEM images of as-produced CNT showed a surface almost completely covered by carbon nanotubes. Only a few areas of the images show the catalyst surface. After the purification step, no trace of catalysts could be observed. Some of the SEM images of the as-produced and purified CNT are in Figure S2. TEM images of as-produced CNT show a diameter distribution from $3 \mathrm{~nm}$ to $20 \mathrm{~nm}$ for all samples, the histograms are in Figure 4 (a). The diameter distributions of CNT.5Co10 $\mathrm{Mo}_{\text {Imp }}$ and $\mathrm{CNT} .5 \mathrm{Co} 10 \mathrm{Mo}_{\mathrm{SG}}$ samples were similar with an average diameter of 8.1 and $9.0 \mathrm{~nm}$, respectively, and they show the same standard deviation, $3.5 \mathrm{~nm}$. Also, the carbon nanotubes produced by $5 \mathrm{Co} 10 \mathrm{Mo}_{\text {Imp }}$ and $5 \mathrm{Co} 10 \mathrm{Mo}_{\mathrm{SG}}$ catalysts are well-structured. Figure 4 (b) shows a well-structured CNT from sample CNT.5Co10Mo ${ }_{\mathrm{SG}}$.

The values of the standard deviation of the carbon nanotube diameter produced by catalysts with $20 \mathrm{wt} . \%$ of Mo were higher than those produced by catalysts with $10 \mathrm{wt} \%$ of Mo, $4.1 \mathrm{~nm}$ for CNT.5Co20Mo $\mathrm{Mmp}_{\text {Im }}$ and $4.7 \mathrm{~nm}$ for the CNT.5Co20 $\mathrm{Mo}_{\mathrm{SG}}$ sample. Moreover, some defective filaments were found in those samples, such as bamboo-like MWNT, described as nanotubes with spaced hollow compartments divided by graphite layers perpendicularly oriented (Lin et al., 2007). Figure 4 (c) is an example of these structures. The formation of a bamboo-like structure may happen when the rate of carbon decomposition is higher than the CNT growth rate as found by Son et al., (2008). The CNT growth rate depends on parameters such as reaction temperature, carbon source and catalyst properties. These parameters are constant in our experiments except for catalyst properties. However, cobalt is the active phase in CNT production and all catalysts have the same cobalt loading (5 wt.\%). Therefore, all catalysts should have, approximately, the same CNT growth rate. But, the rate of carbon decomposition is also dependent on the molybdenum loading. Molybdenum is active for methane decomposition (Ni et al., 2009). This may explain the formation of bamboo-like structures in the catalyst with higher molybdenum loading.

The TEM images exhibited encapsulated metal particles inside the CNT, indicating an incomplete 
removal of the catalyst in the purification step, as shown in Figure S3. These particles are usually active particles for CNT growth. However, there are no large gray areas as found in as-produced samples. This points to an efficient removal of the catalyst support. The purified CNT were also analyzed by TEM, EDX,
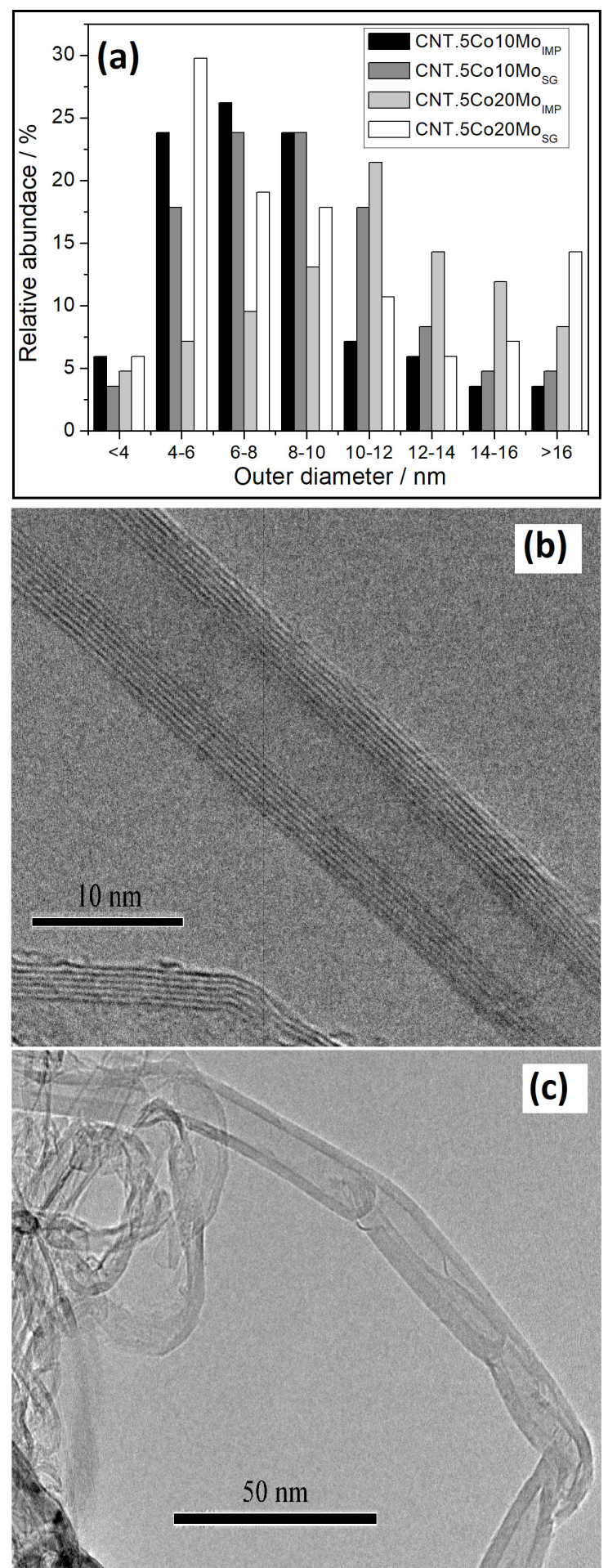

Figure 4. (a) Diameter distribution histograms for as-produced CNT; (b) and (c) TEM images of the as-produced $\mathrm{CNT}$ samples $\mathrm{CNT} .5 \mathrm{Co} 10 \mathrm{Mo}_{\mathrm{SG}}$ and CNT.5Co20Mo $\mathrm{Mmp}_{\text {Imp }}$, respectively.
XRD, TPO and Raman spectroscopy. The images also showed a few CNT with structural defects in the external walls. This indicates that the purification step may damage the CNT surface. The degree of defects was analyzed by Raman spectroscopy and will be discussed further.

The catalyst selectivity toward MWNT was determined by TPO analysis. Usually, SWNT and amorphous carbon are produced with MWNT. However, these carbon species oxidize at different temperatures. Amorphous carbon is the first species to be oxidized followed by SWNT and MWNT (Wang et al., 2012). TPO profiles of as-produced CNT showed a single oxidation peak in the range of $550-590{ }^{\circ} \mathrm{C}$, as shown in Figure S4. This peak is within the oxidation temperature range of MWNT. The absence of peaks between $300-500{ }^{\circ} \mathrm{C}$ indicates a low production of amorphous carbon and SWNT, as indicated by TEM images.

In the methane decomposition reaction, a fraction of $\mathrm{MoO}_{\mathrm{x}}$ is also transformed into $\mathrm{Mo}_{2} \mathrm{C}$, as discussed later and in TPO analyses, it can be oxidized to $\mathrm{MoO}_{\mathrm{x}}$ and $\mathrm{CO}$. However, the amount of carbon in the form of $\mathrm{Mo}_{2} \mathrm{C}$ after carbon nanotube production is very small, even for catalyst with $20 \mathrm{Wt}$.\% of molybdenum. Then, these other minor forms of carbon such as graphene, amorphous carbon and $\mathrm{Mo}_{2} \mathrm{C}$ were not taken into account in the carbon nanotube purity expression, Equation (2).

After the purification step, the TPO profiles shifted to high oxidation temperatures. This behavior could be attributed to the partial removal of the catalyst during purification. The catalyst can speed up the process of oxidation of the carbon deposits, leading to lower oxidation temperatures (Abdullahi et al., 2013)

CNT structure was studied by Raman spectroscopy, for which results are depicted in Figure 5. More than ten different spots were analyzed for each sample. The graphitization of the carbon species was evaluated through the average values of the ratio of $D$ and $G$ band intensities $\left(\mathrm{I}_{\mathrm{D}} / \mathrm{I}_{\mathrm{G}}\right)$. The G-band, in the range of $1500-1600 \mathrm{~cm}^{-1}$, is related to the tangential stretching of the $\mathrm{C}-\mathrm{C}$ bond in the graphene layer. The structural defects of the produced CNT and the presence of disordered carbon materials were observed through the identification of the D-band in the range of 1250-1350 $\mathrm{cm}^{-1}$. (Wang et al., 2012; Abdullahi et al., 2013).

The CNT produced from catalysts with 10 wt. $\%$ of molybdenum exhibited higher degrees of graphitization than the catalysts with 20 wt.\% as observed in TEM images. Flahaut et al. (2004) also observed an increase in $\mathrm{I}_{\mathrm{D}} / \mathrm{I}_{\mathrm{G}}$ ratio with the increase of molybdenum loading. Figure 5 (a-d) shows the Raman spectra of the as-produced CNT and their average $\mathrm{I}_{\mathrm{D}} / \mathrm{I}_{\mathrm{G}}$ ratio. The $\mathrm{I}_{\mathrm{D}} / \mathrm{I}_{\mathrm{G}}$ ratio average values of the as-produced 


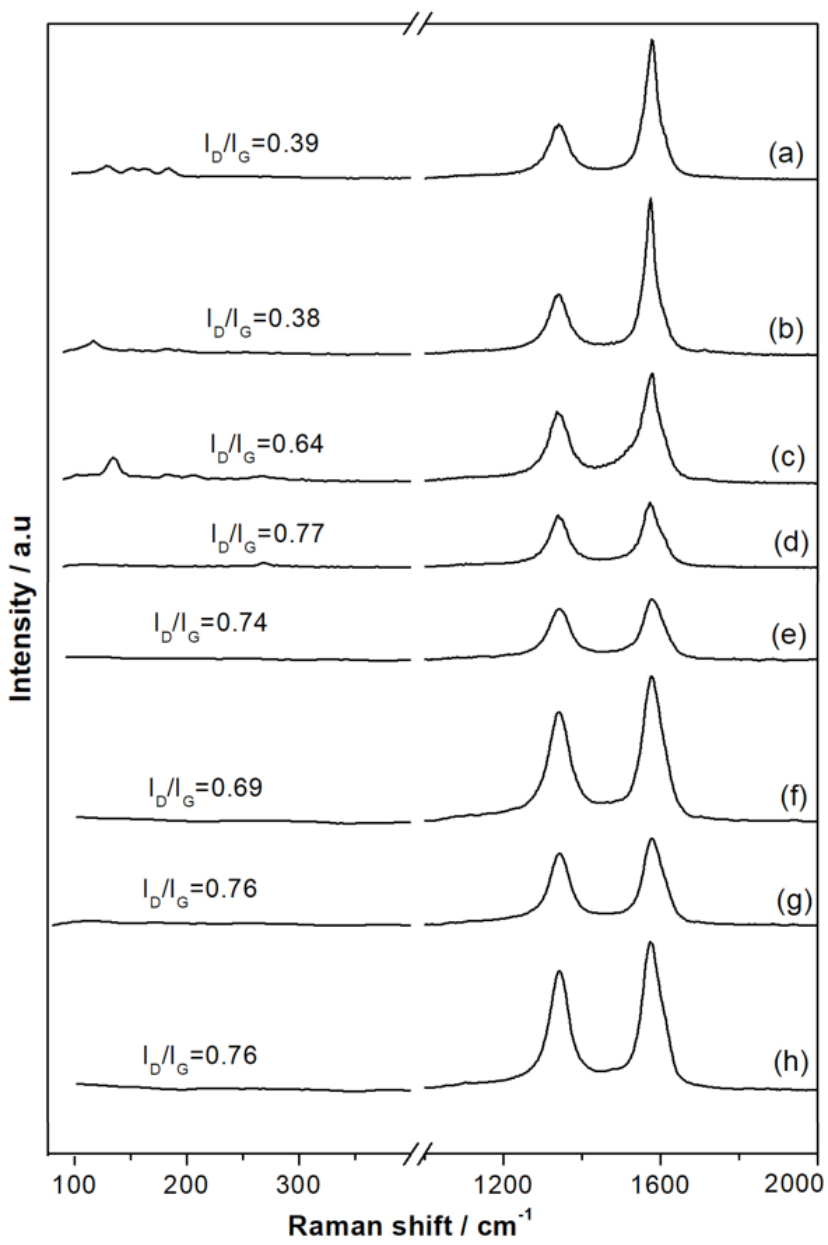

Figure 5. Raman spectra of $\mathrm{CNT}$ as-produced: (a) CNT.5Co10Mo $\mathrm{M}_{\text {Imp }}$, (b) CNT.5Co10 $\mathrm{Mo}_{\mathrm{SG}}$, (c)

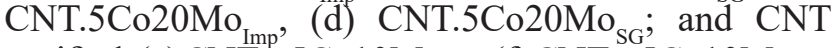
purified:(e)CNTp. $5 \mathrm{Co} 10 \mathrm{Mo}_{\mathrm{Imp}}$, (f)CNTp. $5 \mathrm{Co} 10 \mathrm{Mo}_{\mathrm{SG}}$, (g) CNTp. $5 \mathrm{Co} 20 \mathrm{Mo}_{\text {Imp }}$, (h) CNTp.5Co20 Mo ${ }_{S G} \cdot I_{D} / I_{G}$ ratio are the average values of the ratio of $D$ and $G$ band intensities obtained for 15 different points for each sample.

CNT are comparable with $\mathrm{I}_{\mathrm{D}} / \mathrm{I}_{\mathrm{G}}$ ratio values observed in high yield of MWNT obtained by other authors in similar experimental conditions (Son et al., 2008; Awadallah et al., 2014).

In some Raman spectra of each sample, there was a low intensity band in the range of $100-400 \mathrm{~cm}^{-1}$. Most of these bands are not in the range of catalyst species such as $\mathrm{Co}_{3} \mathrm{O}_{4}, \mathrm{CoMoO}_{4}, \mathrm{MoO}_{3}, \mathrm{MgMoO}_{4}$. Thus, these bands were related to the radial breathing mode (RBM) vibration of SWNT (Abdullahi et al., 2013) .

Raman results showed that the purification process increased the degree of disordering of the CNT samples by the increase of $\mathrm{I}_{\mathrm{D}} / \mathrm{I}_{\mathrm{G}}$ ratio values (Ling et al. 2013). The $\mathrm{I}_{\mathrm{D}} / \mathrm{I}_{\mathrm{G}}$ ratios of purified samples Figure 5 (e-h) were slightly higher than the $\mathrm{I}_{\mathrm{D}} / \mathrm{I}_{\mathrm{G}}$ ratios of the asproduced CNT and showed average values lower than 0.8 (Figure 5 (a-d). The most affected as-produced CNT were those with low $I_{D} / I_{G}$, i.e. catalysts with 10 wt. \% of molybdenum. Huang et al. (2003) studied the purification of MWNT with $\mathrm{I}_{\mathrm{D}} / \mathrm{I}_{\mathrm{G}}$ ratio values higher than 0.8 and they found that $I_{D} / I_{G}$ values of the purified MWNT were not significantly affected by the acid treatment.

The characteristic vibrational modes of $\mathrm{Co}_{3} \mathrm{O}_{4}$, $\mathrm{MgMoO}_{4}, \mathrm{CoMoO}_{4}$ and $\mathrm{MoO}_{3}$ observed in calcined catalyst, see Figure 3, were not detected after CVD reaction, see Figure S5, probably due to the high carbon content in the samples.

Weight loss curves of as-produced and purified CNT are shown in Figure 6 (a) and (b), respectively. The large weight loss between 450 and $700{ }^{\circ} \mathrm{C}$ is associated with oxidation of MWNT as demonstrated by TPO results. Carbon yield was calculated from Equation (1) using the weight loss curves of the as-produced CNT and the sample purity was calculated from Equation (2) by means of the weight loss profile of the purified samples. Equations (1) and (2) consider that the weight loss from TGA cannot be attributed only to the
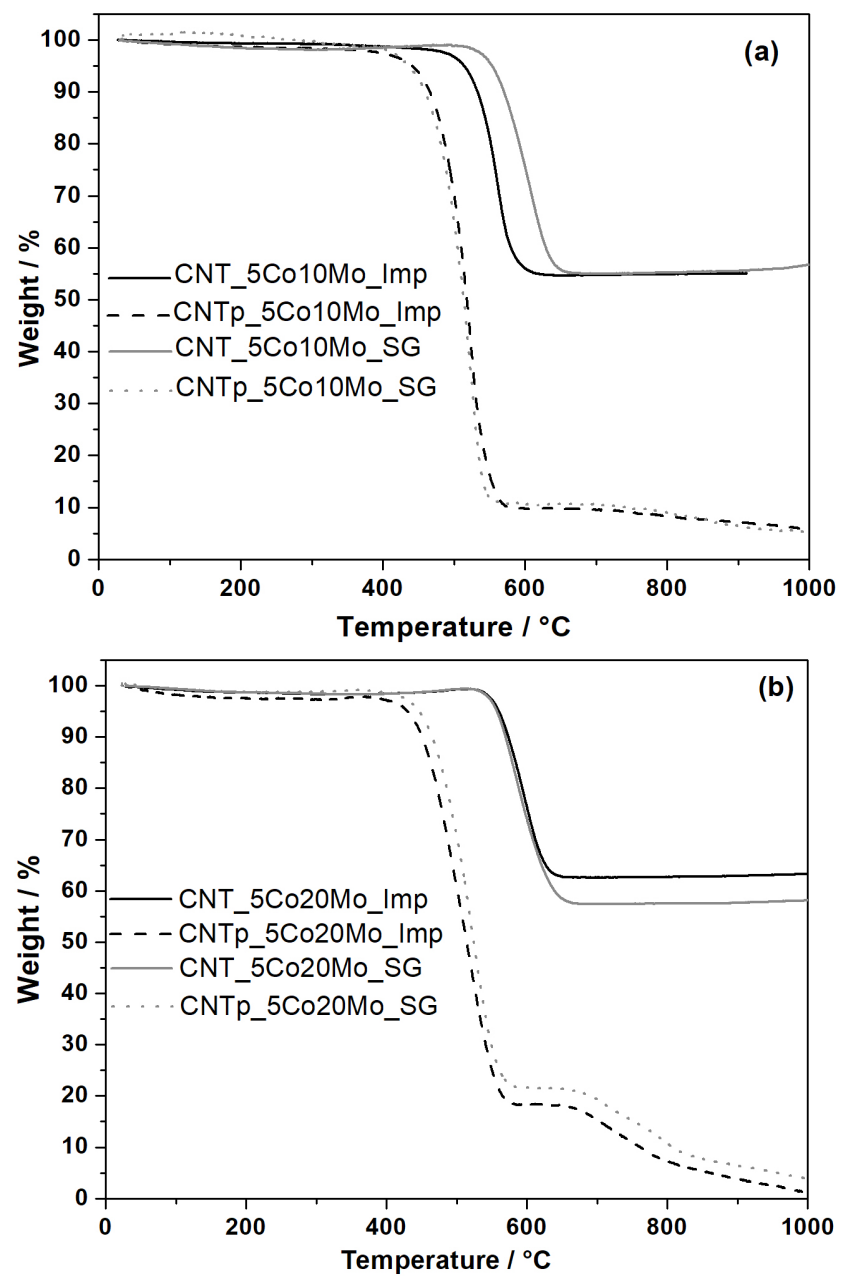

Figure 6. Weight loss curves: (a) as-produced and purified CNT produced by $5 \mathrm{Co}^{\mathrm{C}} 10 \mathrm{Mo}_{\mathrm{Imp}}$ and $5 \mathrm{Co} 10 \mathrm{Mo}_{\mathrm{SG}}$ catalysts; (b) as-produced and purified CNT produced by $5 \mathrm{Co} 20 \mathrm{Mo}_{\mathrm{Imp}}$ and $5 \mathrm{Co} 20 \mathrm{Mo}_{\mathrm{SG}}$ catalysts. 
oxidation of carbon species. Cobalt and molybdenum also get oxidized during the experiment. This means that the fraction of carbon is higher than the resulting weight loss due to the weight gain compensation related to the simultaneous oxidation of metals.

The $5 \mathrm{Co} 10 \mathrm{Mo}_{\mathrm{Imp}}$ and $5 \mathrm{Co} 10 \mathrm{Mo}_{\mathrm{SG}}$ catalysts showed the highest carbon yield, 88 and $85 \%$, respectively, while the catalysts with $20 \mathrm{wt} \%$ of molybdenum showed lower carbon yield, $68 \%$ for $5 \mathrm{Co} 20 \mathrm{Mo}_{\text {Imm }}$ and $81 \%$ for $5 \mathrm{Co} 20 \mathrm{Mo}_{\mathrm{SG}}$. Also, the purified samples produced by catalysts with 20 wt.\% of molybdenum showed a significant weight loss between $600-1000^{\circ} \mathrm{C}$. This weight loss may be attributed to sublimation of $\mathrm{MoO}_{3}$ formed from the oxidation of $\mathrm{Mo}_{2} \mathrm{C}$ also detected in DRX results (Figure 7). $\mathrm{Mo}_{2} \mathrm{C}$ oxidation has already been studied and it is known that it starts around $450{ }^{\circ} \mathrm{C}$ and may be completed with the formation of $\mathrm{MoO}_{3}$ at $550{ }^{\circ} \mathrm{C}$. Then, increasing the temperature, $\mathrm{MoO}_{3}$ sublimation occurs around $700{ }^{\circ} \mathrm{C}$ (Chen et al., 2011).

After the purification process, there was a complete removal of the catalyst support. No traces of $\mathrm{Mg}$ $\mathrm{X}$-ray lines were detected in EDX analyses. However, only a fraction of the cobalt and molybdenum were removed. The composition of the purified samples is reported in Table 2. The degree of catalyst elements extraction from as-produced CNT was calculated from EDX and TG results. The fraction of cobalt and molybdenum removed from CNT.5Co10Mo $\mathrm{Mmp}_{\text {Imp }}$ was similar $(60 \%$ Co and $62 \% \mathrm{Mo})$ and the same trend was observed for CNT.5Co10Mo $\mathrm{MG}_{\mathrm{SG}}$ (46\% Co and 49 $\% \mathrm{Mo})$. However, for catalysts with high molybdenum loading, the proportion of cobalt removed was higher than molybdenum.

The identification of the residual catalyst compounds was also determined by XRD analyses. Figure 7 shows

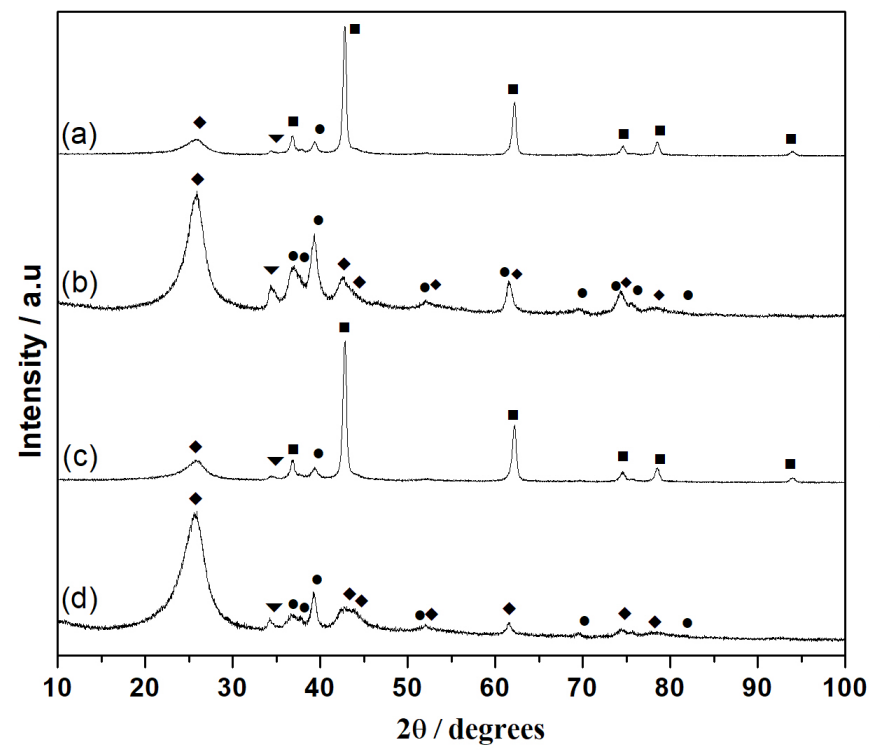

XRD results for as-produced and purified CNT. From XRD patterns of as-produced CNT (Figure 7 (a), (c), (e) and (g)) four compounds were identified: a broad peak at $2 \theta=26.5^{\circ}$ related to carbon nanotubes (Belin and Epron, 2005), strong $\mathrm{MgO}$ peaks, weak $\mathrm{Mo}_{2} \mathrm{C}$ peaks at $2 \theta=34.4^{\circ} ; 38^{\circ} ; 39.3^{\circ} ; 52.1^{\circ} ; 69.6^{\circ} ; 72.4^{\circ}$; $75.5^{\circ} ; 81.2^{\circ}$ e $84.8^{\circ}$; and weak peaks from $\mathrm{CoMoO}_{4}$ or $\mathrm{MgMoO}_{4}$ (these compounds presented overlapped diffraction lines).

After the purification step, $\mathrm{MgO}$ diffraction peaks were eliminated in all samples (Figure 7 (b), (d), (f) and (h)) which is in agreement with the EDX results. The position of peaks characteristic of $\mathrm{MgMoO}_{4}$ or $\mathrm{CoMoO}_{4}$ did not disappear after the purification step. Moreover, no traces of Mg X-ray lines were detected in EDX analyses of the purified samples. Thus, these diffraction lines were ascribed to $\mathrm{CoMoO}_{4}$. The ratio between the area of the most intense peak of MWNT at $26.5^{\circ}$ and the area of the peak of $\mathrm{CoMoO}_{4}$ at $34.4^{\circ}$ increased after the purification step due to the complete removal of the $\mathrm{MgMoO}_{4}$ or due to the partial removal of $\mathrm{CoMoO}_{4}$ or both. The $\mathrm{Mo}_{2} \mathrm{C}$ species were formed during the CVD method as found by Xu et al. (2011). However, it is not clear if $\mathrm{Mo}_{2} \mathrm{C}$ come from $\mathrm{MoO}_{3}$, $\mathrm{MgMoO}_{4}$ or $\mathrm{CoMoO}_{4}$

As observed in Table 2, the purification process was more efficient for as-produced CNT synthetized with impregnated catalysts than those prepared by the sol-gel method. The catalysts prepared by the sol-gel method have a higher fraction of cobalt in the form of $\mathrm{CoMoO}_{4}$, which has low solubility in acidic solutions. The mass of residual catalyst particles in purified samples was determined by TG and their composition by EDX.

$5 \mathrm{Co} 10 \mathrm{Mo}_{\text {Imp }}$ catalyst showed the best performance for CNT production. It produced more uniform and well-structured nanotubes with good production

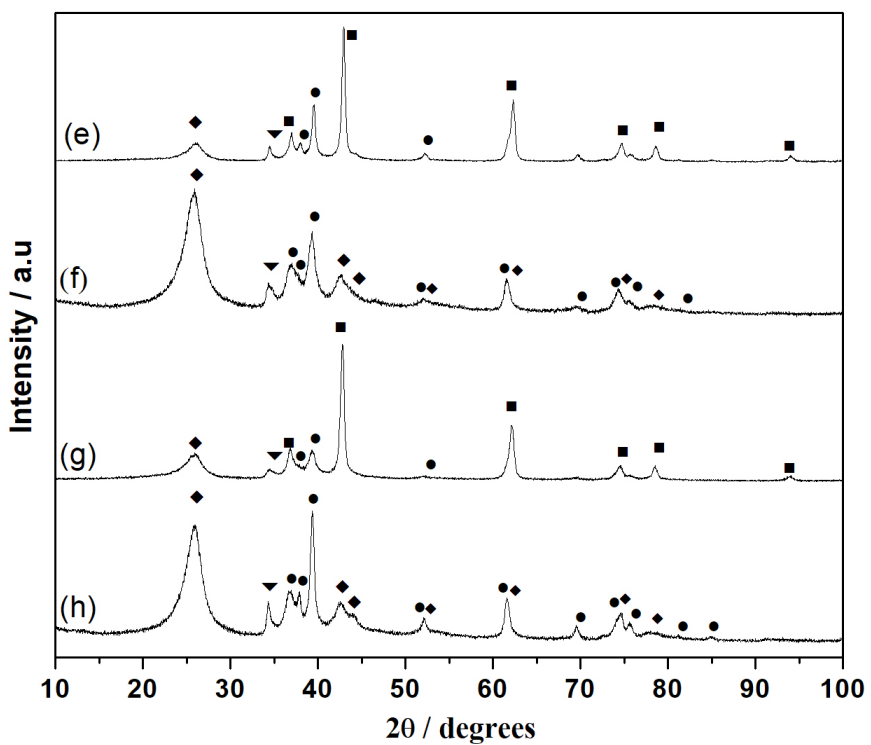

Figure 7. XRD patterns of as-produced and purified CNT: (a) $\mathrm{CNT}^{2} \mathrm{Co} 10 \mathrm{Mo}_{\text {Imp }}$; (b) $\mathrm{CNTp} .5 \mathrm{Co} 10 \mathrm{Mo}_{\text {Imp }}$;

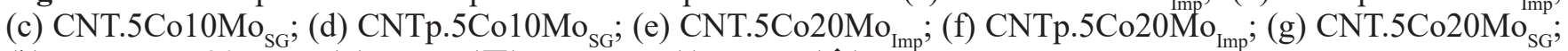
(h) $\mathrm{CNTp} .5 \mathrm{Co} 20 \mathrm{Mo}_{\mathrm{SG}^{*}}(\mathbf{\bullet}) \mathrm{MgO},(\boldsymbol{\nabla}) \mathrm{CoMoO}_{4},(\bullet) \mathrm{Mo}_{2} \mathrm{C},(\bullet) \mathrm{MWNT}$. 
Table 2. Degree of catalyst element extraction from as-produced CNT and composition of purified CNT.

\begin{tabular}{|c|c|c|c|c|c|c|c|}
\hline \multirow{3}{*}{ Samples } & \multicolumn{3}{|c|}{ As-produced CNT } & \multicolumn{4}{|c|}{ Purified CNT } \\
\hline & \multicolumn{3}{|c|}{ Extraction of catalyst elements / wt.\% } & \multicolumn{4}{|c|}{ Sample composition / wt. \% } \\
\hline & Co & Mo & Mg & Co & Mo & MgO & C \\
\hline 5Co10MoImp & 60 & 62 & 100 & 2.3 & 4.6 & 0 & 93.1 \\
\hline 5Co10Mosg & 46 & 49 & 100 & 2.9 & 4.7 & 0 & 92.4 \\
\hline 5Co20MoImp & 69 & 52 & 100 & 1.7 & 11.2 & 0 & 87.1 \\
\hline $5 \mathrm{Co} 20 \mathrm{MosG}$ & 53 & 21 & 100 & 2.1 & 12.8 & 0 & 85.1 \\
\hline
\end{tabular}

performance. Also, the purification process was able to completely remove the catalyst support and most of the cobalt and molybdenum from the CNT_5Co10Mo Imp sample. Therefore, $5 \mathrm{Co} 10 \mathrm{Mo}_{\mathrm{Imp}}$ catalyst was chosen for new catalytic tests. The reaction time was increased (60 $\mathrm{min}, 120 \mathrm{~min}$. and $180 \mathrm{~min}$ ) to evaluate the evolution of the carbon yield and the catalyst deactivation. The as-produced CNT were named CNT_60', CNT_120' and CNT_180'.

The carbon yield in function of the reaction time is linear, indicating that no significant catalyst deactivation was observed, as can be seen in Figure 8. $\mathrm{Ni}$ et al. (2006) studied the kinetics of carbon nanotube growth over $\mathrm{Mo} / \mathrm{Co} / \mathrm{MgO}$ catalysts and, for most of the catalytic tests, the authors observed a decrease in reaction rate only after $180 \mathrm{~min}$.

Usually, long reactions time are essential to achieve high yield of MWNT. Also, the empty volume of the reactor must be large to allow an efficient growth of the MWNT. For example, at the beginning of the reaction of the CNT_180' sample, the catalyst occupies only a small fraction of the reactor volume, smaller than 5 $\%$. Then, as the carbon nanotubes grow, they fill the reactor. After $180 \mathrm{~min}$ of reaction, the carbon yield was $360 \%$ and the reactor was almost full. Thus, no further reaction time was tested.

The purification of the CNT_30', CNT_60', CNT_120' and CNT_180' samples showed a complete removal of $\mathrm{MgO}$ and a partial removal of $\mathrm{Co}$ and $\mathrm{Mo}$

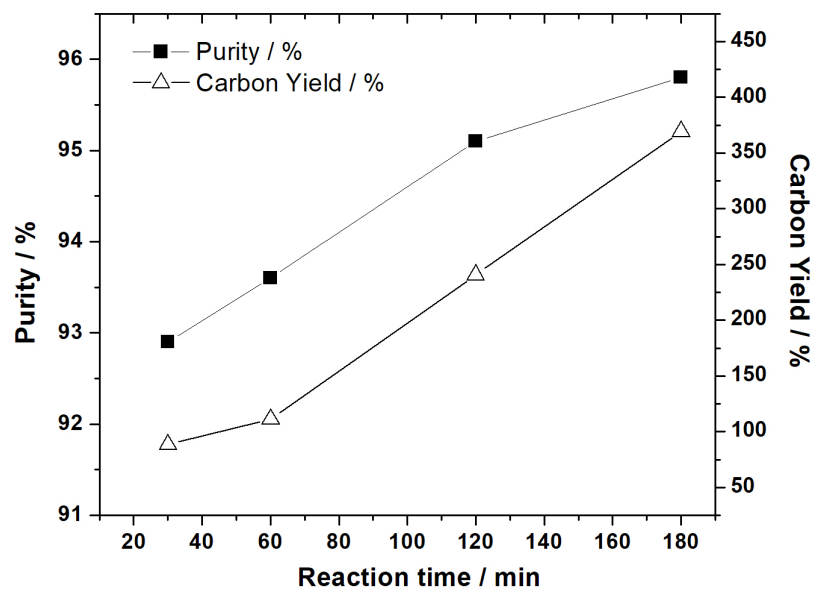

Figure 8. Carbon yield for the $5 \mathrm{Co} 10 \mathrm{Mo}_{\text {Imp }}$ catalyst and sample purity after the purification process. The carbon yield and purity were calculated by equations 1 and 2 , respectively. from CNT. The sample purity was estimated by Eq. (2). The residual weight of CNT 30 ' is $10.0 \%$, which implies that approximately $92.9 \%$ of the mass of the sample is carbon, considering the weight fraction of cobalt and molybdenum in the sample and its conversion to oxide in the process of TGA analysis. The degree of purification of these samples increased with increasing carbon yield, from $92.9 \%$ for the CNT $30^{\prime}$ sample to $95.8 \%$ for the CNT $180^{\prime}$ sample, as can be seen in Figure 8.

\section{CONCLUSIONS}

The catalysts prepared by sol-gel method improved the interaction between cobalt and molybdenum, increasing the formation of $\mathrm{CoMoO}_{4}$ and decreasing the formation of $\mathrm{Co}_{3} \mathrm{O}_{4}$ and $\mathrm{CoO}$. This interaction was also higher for the catalysts with 20 wt.\% of molybdenum than those with $10 \mathrm{wt} . \%$. The excess of molybdenum decreased the carbon yield and produced CNT with lower degree of graphitization.

The purification step by mild acid treatment was effective to remove all $\mathrm{MgO}$ and a major fraction of the cobalt and molybdenum present in CNT samples without significant damage to the carbon nanotube structure. The purification process was more efficient for as-produced CNT synthetized with impregnated catalysts than those synthetized with catalysts prepared by the sol-gel method. The catalysts prepared by the sol-gel method presented a higher fraction of cobalt in the form of $\mathrm{CoMoO}_{4}$, which has low solubility in acidic solutions.

High yields of MWNT produced by methane chemical vapor deposition on $\mathrm{CoMo} / \mathrm{MgO}$ catalysts cannot be free of impurities after purification by mild acid treatment. The cobalt and molybdenum particles inside the carbon nanotubes could not be completely removed. However, an increase in sample purity could be achieved by increasing reaction time. There was no evidence of catalyst deactivation in $180 \mathrm{~min}$ of reaction.

\section{ACKNOWLEDGEMENTS}

This study was financed in part by the Coordenação de Aperfeiçoamento de Pessoal de Nível Superior (CAPES) - Finance Code 001 and Fundação de Amparo à Pesquisa do Estado do Rio de Janeiro (FAPERJ). 


\section{REFERENCES}

Abdullahi I., Sakulchaicharoen N., Herrera J. E. Selective growth of single-walled carbon nanotubes over $\mathrm{Co}-\mathrm{MgO}$ catalyst by chemical vapor deposition of methane. Diam Relat Mater., 38, 1-8 (2013). https://doi.org/10.1016/j.diamond.2013.05.002

Alvarez W. E., Kitiyanan, B., Borgna, A., Resasco, D. E. Synergism of Co and Mo in the catalytic production of single-wall carbon nanotubes by decomposition of CO. Carbon, 39, 547-558 (2001). https://doi.org/10.1016/S0008-6223(00)00173-1

Awadallah, A. E., Aboul-Enein, A. A., Aboul-Gheit, A. K. Impact of group VI metals addition to $\mathrm{Co} /$ $\mathrm{MgO}$ catalyst for non-oxidative decomposition of methane into COx-free hydrogen and carbon nanotubes. Fuel, 129, 27-36 (2014). https://doi. org/10.1016/j.fuel.2014.03.038

Belin, T., Epron, F. Characterization methods of carbon nanotubes: a review. Mater Sci Eng B, 119, 105-118 (2005). https://doi.org/10.1016/j. mseb.2005.02.046

Chai, S., Lee, K., Ichikawa, S., Rahman, A. Synthesis of carbon nanotubes by methane decomposition over Co- Mo/Al2O3 : Process study and optimization using response surface methodology. Appl Catal A Gen, 396, 52-58 (2011). https://doi.org/10.1016/j. apcata.2011.01.038

Chang, S.-C., Leugers, M. A., Bare, S. R. Surface Chemlstry of Magnesium Oxide-Supported Molybdenum Oxide: An In Situ Raman Spectroscoplc Study. J Phys Chem, 96, 1035810365 (1992). https://doi.org/10.1021/j100204a048

Chen, Y., Zhang, H., Zhang, J., Ma, J., Ye, H., Qian, G., Ye, Y., Zhong, S. Facile Synthesis and Thermal Stability of Nanocrystalline Molybdenum Carbide. Mater Sci Appl, 2, 1313-1316 (2011). https://doi. org/10.4236/msa.2011.29178

De Volder, M. F. L., Tawfick, S. H., Baughman, R. H., Hart, A. J. Carbon nanotubes: present and future commercial applications. Science, 339, 535-539 (2013). https://doi.org/10.1126/science.1222453

Flahaut, E., Bacsa, R., Peigney, A., Laurent, C. Gramscale CCVD synthesis of double-walled carbon nanotubes. Chem Commun, 12, 1442-1443 (2003). https://doi.org/10.1039/b301514a

Flahaut, E., Peigney, A., Bacsa, W. S., Basca, R. R., Laurent, C. CCVD synthesis of carbon nanotubes from $(\mathrm{Mg}, \mathrm{Co}, \mathrm{Mo}) \mathrm{O}$ catalysts: influence of the proportions of cobalt and molybdenum. J Mater Chem, 14, 646-653 (2004). https://doi.org/10.1039/ b312367g

Gwag, J. S., Sohn, Y. Interfacial natures and controlling morphology of Co oxide nanocrystal structures by adding spectator Ni ions. Bull Korean Chem Soc, 33, 505-510 (2012). https://doi.org/10.5012/ bkcs.2012.33.2.505
Hench, L. L., West, J. K. The Sol-Gel Process. Chem Rev, 90, 33-72 (1990). https://doi.org/10.1021/ cr00099a003

Huang, W., Wang, Y., Luo, G., Wei, F. 99.9\% Purity Multi-Walled Carbon Nanotubes By Vacuum High-Temperature Annealing. Carbon, 41, 25852590 (2003). https://doi.org/10.1016/S00086223(03)00330-0

Iijima, S. Helical microtubules of graphitic carbon. Nature, 354, 56-58 (1991). https://doi. org $/ 10.1038 / 354056 \mathrm{a} 0$

Jourdain, V., Bichara, C. Current understanding of the growth of carbon nanotubes in catalytic chemical vapour deposition. Carbon, 58, 2-39 (2013). https:// doi.org/10.1016/j.carbon.2013.02.046

Kaluža, L., Gulková, D., Vít, Z. Zdražil M., Effect of support type on the magnitude of synergism and promotion in CoMo sulphide hydrodesulphurisation catalyst. Appl Catal A Gen, 324, 30-35 (2007). https://doi.org/10.1016/j.apcata.2007.02.050

Kitiyanan, B., Alvarez, W. E., Harwell, J. H., Resasco, D. E. Controlled production of single-wall carbon nanotubes by catalytic decomposition of $\mathrm{CO}$ on bimetallic Co-Mo catalysts. Chem Phys Lett, 317, 497-503 (2000). https://doi.org/10.1016/S00092614(99)01379-2

Lin, M., Tan, J. P. Y., Boothroyd, C., Loh, K. P., Tok, E. S., Foo, Y. L. Dynamical observation of bamboolike carbon nanotube growth. Nano Lett, 7, 22342238 (2007). https://doi.org/10.1021/n1070681x

Ling, X., Wei, Y., Zou, L., Xu, S. The effect of different order of purification treatments on the purity of multiwalled carbon nanotubes. Appl Surf Sci, 276, 159-166, (2013). https://doi.org/10.1016/j. apsusc.2013.03.056

Liu, W.-W., Chai, S.-P., Mohamed, A. R., Hashim, U. Synthesis and characterization of graphene and carbon nanotubes: A review on the past and recent developments. J Ind Eng Chem, 20, 1171-1185 (2014). https://doi.org/10.1016/j.jiec.2013.08.028

Mcintyre, N. S., Johnston, D. D., Coatsworth, L. L., Davidson, R. D., Brown, J. R. X-ray Photoelectron Spectroscopic Studies of Thin Film Oxides of Cobalt and Molybdenum. Surf Interface Anal, 15, 265-272 (1990). https://doi.org/10.1002/ sia. 740150406

Medema, J., Stam, C. van, Beer, V. H. J. de, Konings, A. J. A., Koningsberger, D. C. Raman Spectroscopic Study of Co-Mo/ $\gamma$-Al2O3 Catalysts, J Catal, 53, 386-400 (1978). https://doi.org/10.1016/00219517(78)90110-0

Milone, C., Piperopoulos, E., Lanza, M., Santangelo, S., Malara, A., Mastronardo, E., Galvagno, S. Influence of the Cobalt Phase on the Highly Efficient Growth of MWNTs. Nanomater Nanotechnol, 4, 1-8 (2014). https://doi.org/10.5772/58457 
Mohanapriya, S., Lakshminarayanan, V. Simultaneous purification and spectrophotometric determination of nickel present in as-prepared single-walled carbon nanotubes (SWCNT). Talanta, 71, 493-497 (2007). https://doi.org/10.1016/j. talanta.2006.04.001

Moura, A. P. de, Oliveira, L. H. de, Pereira, P. F. S, Rosa, I. L. V., Li, M. S., Longo, E., Varela, J. A. Photoluminescent Properties of CoMoO4 Nanorods Quickly Synthesized and Annealed In a Domestic Microwave Oven. Adv Chem Eng Sci, 2, 465-473 (2012). https://doi.org/10.4236/aces.2012.24057

Ni, L., Kuroda, K., Zhou, L.-P., Kizuka, T., Ohta, K., Matsuishi, K., Nakamura, J. Kinetic study of carbon nanotube synthesis over $\mathrm{Mo} / \mathrm{Co} / \mathrm{MgO}$ catalysts. Carbon, 44, 2265-2272 (2006). https:// doi.org/10.1016/j.carbon.2006.02.031

Ni, L., Kuroda, K., Zhou, L. P., Kizuka, T., Ohta, K., Matsuishi, K., Nakamura, J. Decomposition of metal carbides as an elementary step of carbon nanotube synthesis. Carbon, 47, 3054-3062 (2009). https://doi.org/10.1016/j.carbon.2009.07.009

Núñez, J. D., Maser, W. K. Carmen Mayoral M., Andrés J.M., Benito A.M., Platelet-like catalyst design for high yield production of multi-walled carbon nanotubes by catalytic chemical vapor deposition. Carbon, 49, 2483-2491 (2011). https:// doi.org/10.1016/j.carbon.2011.02.018

Parmaliana, A., Arena, F., Frusteri, F., Giordano, N. Temperature-programmed reduction study of $\mathrm{NiO}-\mathrm{MgO}$ interactions in magnesia-supported $\mathrm{Ni}$ catalysts and $\mathrm{NiO}-\mathrm{MgO}$ physical mixture. J Chem Soc Faraday Trans, 86, 2663-2669 (1990). https:// doi.org/10.1039/FT9908602663

Pudukudy, M., Yaakob, Z., Zulhamizan, M., Sobri, M. Environmental one-pot sol-gel synthesis of $\mathrm{MgO}$ nanoparticles supported nickel and iron catalysts for undiluted methane decomposition into $\mathrm{COx}$ free hydrogen and nanocarbon. Appl Catal B, Environ, 218, 298-316 (2017). https://doi.org/10.1016/j. apcatb.2017.04.070

Radwan, N. R., Ghozza, A. M. El-Shobaky G.A., Solid-solid interactions in Co3O4-MoO3/MgO system. Thermochim Acta, 398, 211-221 (2003). https://doi.org/10.1016/S0040-6031(02)00369-6

Rols, S., Righi, A., Alvarez, L., Anglaret, E., Almairac, R., Journet, C., Bernier, P., Sauvajol, J. L., Benito, A. M., Maser, W. K., Muñoz, E., Martinez, M. T., Fuente, G. F. de la, Girard, A., Ameline, J. C. Diameter distribution of single wall carbon nanotubes in nanobundles. Eur. Phys. J. B, 18, 201-205 (2000). https://doi.org/10.1007/ s100510070049

Serquis, A., Liao, X. Z., Huang, J. Y., Peterson, D. E., Zhu, Y. T. Co-Mo catalyzed growth of multi-wall carbon nanotubes from $\mathrm{CO}$ decomposition. Carbon,
41, 2635-2641 (2003). https://doi.org/10.1016/ S0008-6223(03)00377-4

Son, S. Y., Lee, Y., Won, S., Won, S., Lee, D. H. HighQuality Multiwalled Carbon Nanotubes from Catalytic Decomposition of Carboneous Materials in Gas-Solid Fluidized Beds. Ind Eng Chem Res, 47, 2166-2175 (2008). https://doi.org/10.1021/ ie 0711630

Tang, C. W., Wang, C. B., Chien, S. H. Characterization of cobalt oxides studied by FT-IR, Raman, TPR and TG-MS. Thermochim Acta, 473, 68-73 (2008). https://doi.org/10.1016/j.tca.2008.04.015

Tran, K. Y., Heinrichs, B., Colomer, J.-F., Pirard, J.P., Lambert, S. Carbon nanotubes synthesis by the ethylene chemical catalytic vapour deposition (CCVD) process on $\mathrm{Fe}, \mathrm{Co}$, and $\mathrm{Fe}-\mathrm{Co} / \mathrm{Al} 2 \mathrm{O} 3$ sol gel catalysts. Appl Catal A Gen, 318, 63-69 (2007). https://doi.org/10.1016/j.apcata.2006.10.042

Ulla, M. A., Spretz, R., Lombardo, E., Daniell, W., Knõzinger, H. Catalytic combustion of methane on $\mathrm{Co} / \mathrm{MgO}$ : characterisation of active cobalt sites. Appl Catal B Environ, 29, 217-229 (2001). https:// doi.org/10.1016/S0926-3373(00)00204-6

Wang, G., Chen, J., Tian, Y., Jin, Y., Li, Y. Water assisted synthesis of double-walled carbon nanotubes with a narrow diameter distribution from methane over a Co-Mo/MgO catalyst. Catal Today, 183, 26-33 (2012). https://doi.org/10.1016/j. cattod.2011.07.004

Wang, H. Y., Ruckenstein, E. Formation of filamentous carbon during methane decomposition over CoMgO catalysts. Carbon, 40, 1911-1917 (2002). https://doi.org/10.1016/S0008-6223(02)00032-5

Wang, Y., Wang, Z., Yu, X, Li, B., Kang, F., He, Y.B. Hierarchically structured carbon nanomaterials for electrochemical energy storage applications. J Mater Res, 33, 1058-1073 (2018). https://doi. org/10.1557/jmr.2017.464

Xu, X., Huang, S., Yang, Z., Zou, C., Jiang, J., Shang, Z. Controllable synthesis of carbon nanotubes by changing the Mo content in bimetallic Fe$\mathrm{Mo} / \mathrm{MgO}$ catalyst. Mater Chem Phys, 127, 379-384 (2011). https://doi.org/10.1016/j. matchemphys.2011.02.028

Yardimci, A. I., Yilmaz, S., Selamet, Y. The effects of catalyst pretreatment, growth atmosphere and temperature on carbon nanotube synthesis using $\mathrm{Co}-\mathrm{Mo} / \mathrm{MgO}$ catalyst. Diam Relat Mater, 60, 81-86 (2015). https://doi.org/10.1016/j. diamond.2015.10.025

Yeoh, W.-M., Lee, K.-Y., Chai, S.-P., Lee, K.-T., Mohamed, A. R. Synthesis of high purity multiwalled carbon nanotubes over $\mathrm{Co}-\mathrm{Mo} / \mathrm{MgO}$ catalyst by the catalytic chemical vapor deposition of methane, New Carbon Mater, 24, 119-123 (2009). https://doi.org/10.1016/S1872-5805(08)60041-4 
Yeoh, W.-M., Lee, K.-Y., Chai, S.-P., Lee, K.-T., Mohamed, A. R. Effective synthesis of carbon nanotubes via catalytic decomposition of methane: Influence of calcination temperature on metalsupport interaction of Co-Mo/MgO catalyst. J Phys Chem Solids, 74, 1553-1559 (2013). https://doi. org/10.1016/j.jpcs.2013.05.023

\section{APPENDIX}
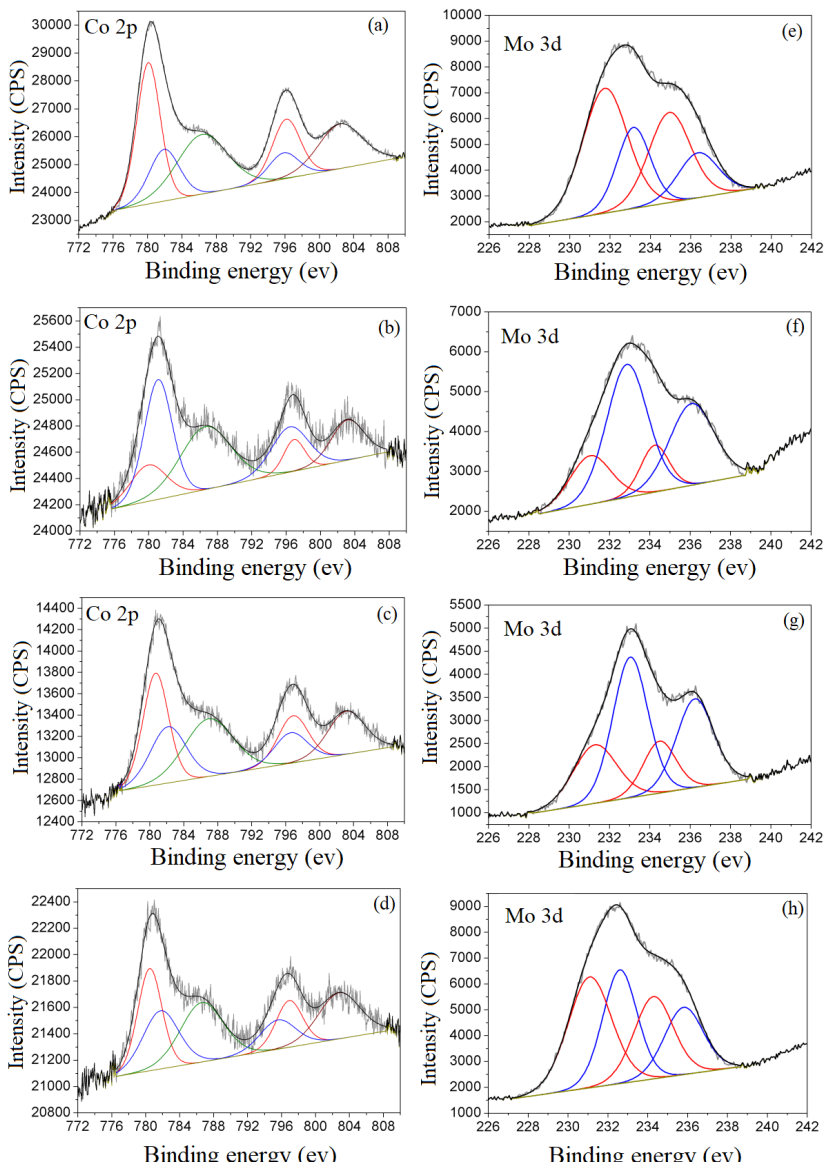

Figure S1. XPS spectra of the calcined catalyst in the Co2p region: (a)5Co10Mo Imp, (b) 5Co10Mo SG, (c) $5 \mathrm{Co} 20 \mathrm{Mo}$ Imp, (d) $5 \mathrm{Co} 20 \mathrm{Mo} \mathrm{SG}$; and in the $\mathrm{Mo}$ 3d region: (e) 5Co10Mo_Imp, (f), 5Co10Mo_SG, (g) 5Co20Mo_Imp, (h) 5Co20Mo_SG.

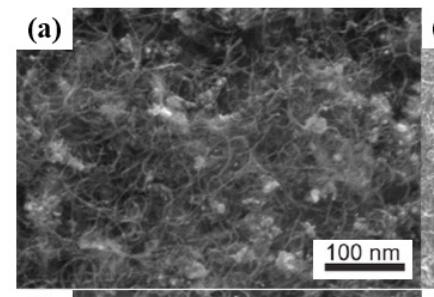

(b)

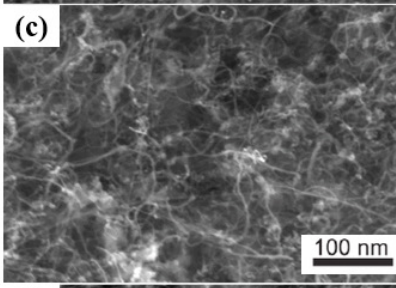

(d)
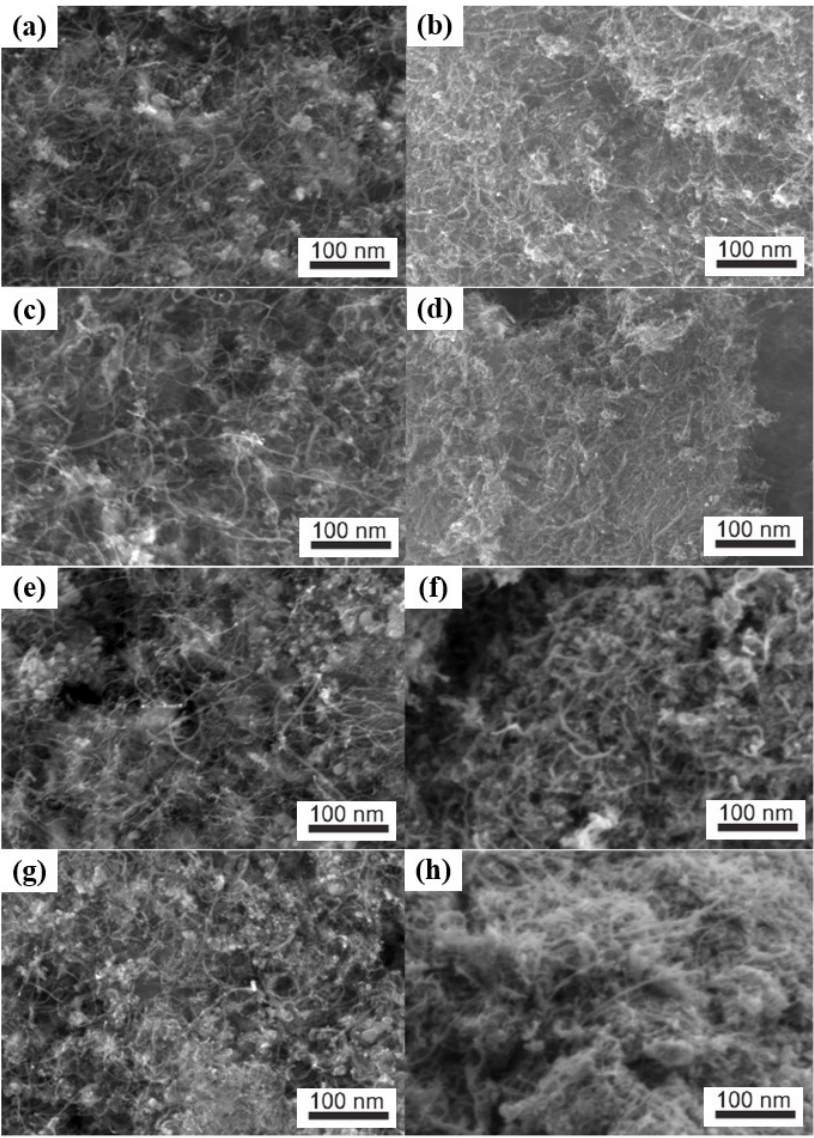

Figure S2. SEM images of the as-produced and purified CNT: (a) CNT.5Co10Mo $\mathrm{Mmp}_{\text {; }}$ (b) CNTp.5Co10Mo $\mathrm{Mmp}_{\text {; }}$ (c) CNT.5Co10Mo $\mathrm{MG}_{\mathrm{S}}$ (d) $\mathrm{CNTp} .5 \mathrm{Co} 10 \mathrm{Mo}_{\mathrm{SG}}$; (e) CNT.5Co20Mo $\mathrm{Mmp}_{\text {Imp }}$ (f) CNTp.5Co20Mo $\mathrm{Mmp}_{\text {;mp }}$; (g) CNT.5Co20Mo $\mathrm{MG}_{\mathrm{SG}}$; (h) CNTp.5Co20Mo $\mathrm{MG}_{\mathrm{S}}$.

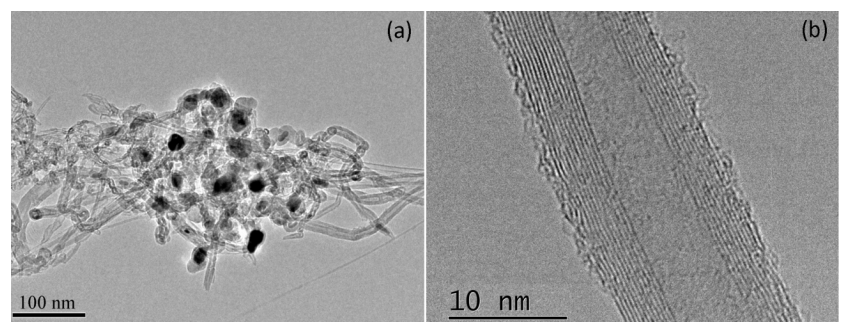

Figure S3. TEM images: (a) CNTp.5Co10Mo $\mathrm{Mg}_{\mathrm{SG}}$ and (b) CNTp.5Co10 Mo $\mathrm{SG}$. 

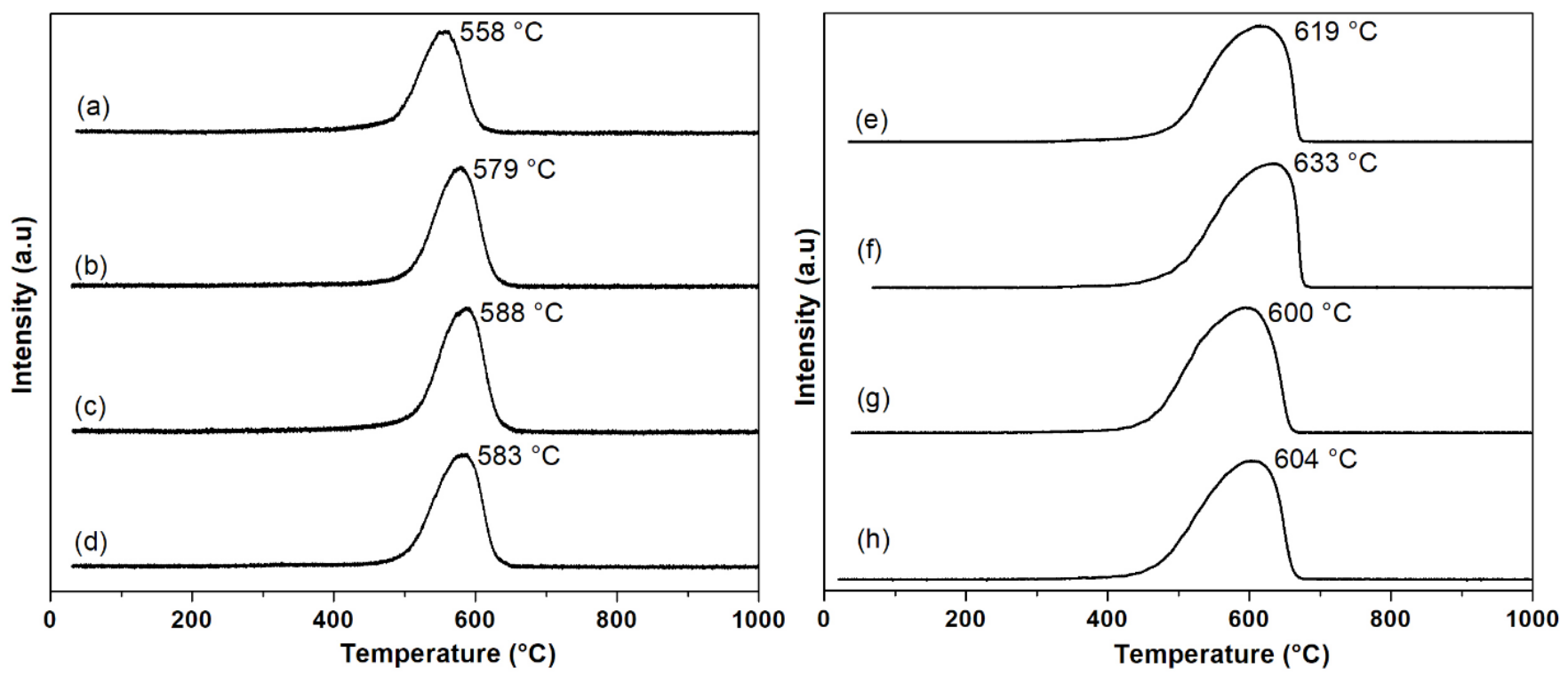

Figure S4. TPO profiles of carbonaceous materials present in as-produced and purified CNT: (a) CNT.5Co10 Mo ;

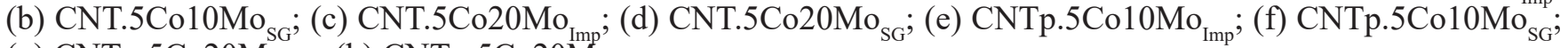
(g) CNTp.5Co20Mo $\mathrm{Mmp}_{\text {; }}$; (h) CNTp.5Co20Mo $\mathrm{MG}_{\text {G }}$.

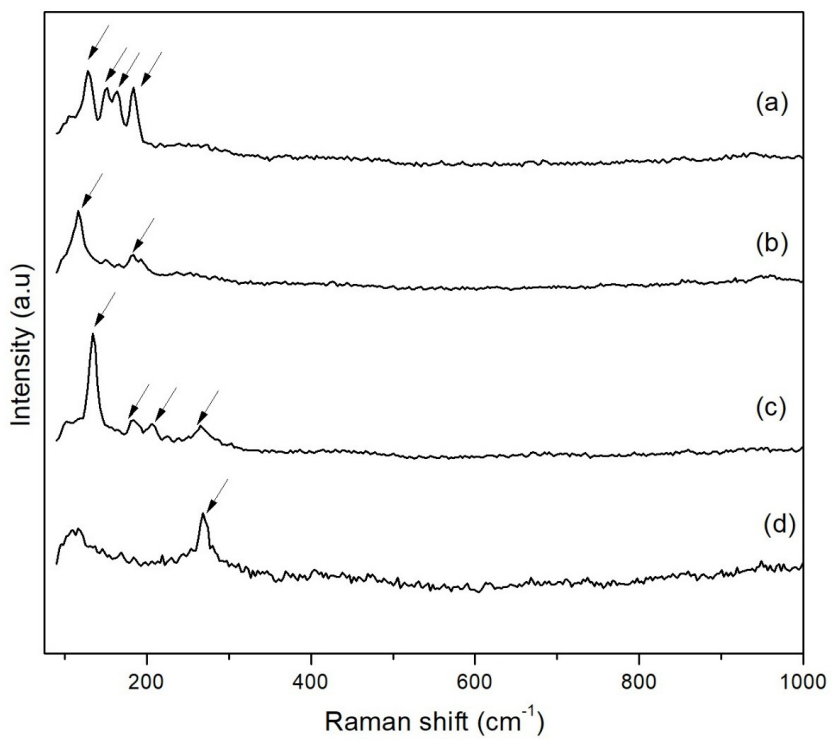

Table S1. Diameter of single walled carbon nanotubes determined by using equation 3 and Raman results.

\begin{tabular}{ccc}
\hline & $\mathbf{v}\left(\mathbf{c m}^{-1}\right)$ & $\boldsymbol{d}(\mathbf{n m})$ \\
\hline & 129 & 1.93 \\
CNT.5Co10MoIMP & 150 & 1.64 \\
& 164 & 1.5 \\
& 184 & 1.32 \\
CNT.5Co10MosG & 117 & 2.15 \\
& 186 & 1.3 \\
CNT.5Co20MoIMP & 135 & 1.85 \\
& 185 & 1.31 \\
CNT.5Co20MosG & 206 & 1.17 \\
& 269 & 0.88 \\
\end{tabular}

FigureS5.Ramanspectraoftheas-producedandpurified CNT: (a) CNT.5Co10Mo ; ; (b) CNT.5Co10Mo $\mathrm{MG}_{\mathrm{SG}}$; (c) CNT.5Co20Mo $\mathrm{Mmp}_{\text {Imp }}$ (d) CNT.5Co20 Mo ${ }_{\mathrm{SG}}$. 